\title{
COORDINATION CHEMISTRY OF WEATHERING: Kinetics of the Surface-Controlled Dissolution of Oxide Minerals
}

\author{
Werner Stumm \\ Institute for Water Resources and \\ Water Pollution Control \\ Swiss Federal Institute of Technology, Zurich
}

\author{
Roland Wollast \\ Laboratoire d'Océanographie Chimique \\ Université Libre de Bruxelles \\ Brussels, Belgium
}

\begin{abstract}
Chemical weathering processes, essentially caused by the interaction of water and the atmosphere with the Earth's crust, transform primary minerals into solutes and clays and, eventually, into sedimentary rocks; these processes participate in controlling the global hydrogeochemical cycles of many elements. Many mineral dissolution processes are controlled by a chemical mechanism at the solid-water interface. The reactioncontrolling steps can be interpreted in terms of a surface coordination model. The tendency of a mineral to dissolve is influenced by the interaction of solutes- $\mathrm{H}^{+}, \mathrm{OH}^{-}$.
\end{abstract}

ligands, and metal ions-with its surface. The surface reactivity is shown to depend on the surface species and their structural identity; specifically, the dependence of dissolution rates on $p \mathrm{H}$ and on dissolved ligand concentrations can be explained in terms of surface protonation (and deprotonation) and of ligand surface complexes. A general rate law for the dissolution of minerals is derived by considering, in addition to the surface coordination chemistry, established models of lattice statistics and activated complex theory.

\section{INTRODUCTION AND OBJECTIVES}

Chemical weathering is one of the major processes controlling the global hydrogeochemical cycle of elements. In this cycle, water operates both as a reactant and as a transporting agent of dissolved and particulate components from land to sea. The atmosphere provides a reservoir for carbon dioxide and for oxidants required in the weathering reactions. The biota assists the weathering processes by providing organic ligands and acids and by supplying locally, upon decomposition, increased $\mathrm{CO}_{2}$ concentrations.

This paper deals with the principal aspects of the chemical weathering of minerals. The objectives are (1) to emphasize that the dissolution of minerals is usually a consequence of reactions occurring at their surfaces and that surface species control the mechanism and the rate of dissolution reactions of oxides and silicates; (2) to postulate a general rate law for the surface-controlled low-temperature dissolution according to which the dissolution rate has a simple dependence on the surface concentration of specific surface species and, specifically, to show that the $p \mathrm{H}$ dependence of dissolution rates can be explained in terms of surface protonation or surface deprotonation; and (3) to develop a mechanistic model that combines concepts of surface coordination chemistry with an established model of lattice statistics and activated complex theory.

In developing our ideas we try to proceed from the simple to the more complex. Thus we illustrate first the basic components of the overall rate law, concentrating primarily on the dissolution of simple oxides. Then we review the coordination chemistry of the oxide-water interface, illustrating that the relatively rapid interaction (adsorption) between solutes, $\mathrm{H}^{+}, \mathrm{OH}^{-}$, metal ions, and ligands with surfaces is experimentally measurable from surface titrations; the surface reactivity (tendency to dissolve) is shown to depend on the surface species and their structural identity.

\section{THE WEATHERING REACTION}

When a mineral dissolves, several successive elementary steps may be involved: (1) mass transport of dissolved reactants from bulk solution to the mineral surface, (2) adsorption of solutes, (3) interlattice transfer of reacting species, (4) chemical reactions, (5) detachment of reactants from the surface, and (6) mass transport into the bulk of the solution. Under natural conditions the rates of dissolution of most minerals are too slow to depend on mass transfer of the reactants or products in the aqueous phase. One can thus restrict the discussion to the case of weathering reactions where the rate-controlling mechanism is the mass transfer of reactants and products in the solid phase or to reactions controlled by a surface reaction and the related detachment process of reactants.

Calcareous minerals and evaporite minerals (halides, gypsum) are very soluble and dissolve rapidly and, in general, congruently (i.e., yielding upon dissolution the same stoichiometric proportions in the solution as the 
proportions in the dissolving mineral and without forming new solid phases). Their contribution to the total dissolved load in rivers can be estimated by considering the mean composition of river water and the relative importance of various rocks to weathering [Garrels and Mackenzie, 1971]. Recent estimates [Holland, 1978; Meybeck, 1979; Wollast and Mackenzie, 1983] indicate that evaporites and carbonates contribute approximately $17 \%$ and $38 \%$, respectively, of the total dissolved load in the world's rivers. The remaining $45 \%$ is due to the weathering of silicates, underlining the significant role of these minerals in the overall chemical denudation of the Earth's surface.

There are no unequivocal weathering reactions for the silicate minerals. Depending on the nature of parent rocks and hydraulic regimes, various secondary minerals like gibbsite, kaolinite, smectites, and illites are formed as reaction products. Some important dissolution processes of silicates are given, for example, by the following reactions:

$$
\begin{aligned}
& \mathrm{CaAl}_{2} \mathrm{Si}_{2} \mathrm{O}_{8}+2 \mathrm{CO}_{2}+3 \mathrm{H}_{2} \mathrm{O} \\
& \text { anorthite } \\
& =\mathrm{Al}_{2} \mathrm{Si}_{2} \mathrm{O}_{5}(\mathrm{OH})_{4}+\mathrm{Ca}^{2+}+2 \mathrm{HCO}_{3}^{-} \\
& \text {kaolinile } \\
& 2 \mathrm{NaAlSi}_{3} \mathrm{O}_{8}+2 \mathrm{CO}_{2}+6 \mathrm{H}_{2} \mathrm{O} \\
& \text { albite } \\
& =\mathrm{Al}_{2} \mathrm{Si}_{4} \mathrm{O}_{10}(\mathrm{OH})_{2}+2 \mathrm{Na}^{+}+2 \mathrm{HCO}_{3}^{-}+2 \mathrm{H}_{4} \mathrm{SiO}_{4} \\
& \mathrm{KMgFe}_{2} \mathrm{AlSi}_{3} \mathrm{O}_{10}(\mathrm{OH})_{2}+\frac{1}{2} \mathrm{O}_{2}+3 \mathrm{CO}_{2}+11 \mathrm{H}_{2} \mathrm{O} \\
& \text { blotite } \\
& =\underset{\text { gibsile }}{\mathrm{Al}(\mathrm{OH})_{3}}+\underset{\text { goethite }}{2 \mathrm{Fe}(\mathrm{OH})_{3}}+\mathrm{K}^{+}+\mathrm{Mg}^{2+}+3 \mathrm{HCO}_{3}^{-}+3 \mathrm{H}_{4} \mathrm{SiO}_{4}
\end{aligned}
$$

In all cases, water and carbonic acid, which is the source of protons, are the main reactants. The net result of the reaction is the release of cations $\left(\mathrm{Ca}^{2+}, \mathrm{Mg}^{2+}, \mathrm{K}^{+}, \mathrm{Na}^{+}\right)$and the production of alkalinity via $\mathrm{HCO}_{3}^{-}$. When ferrous iron is present in the lattice, as in biotite, oxygen consumption may become an important factor affecting the weathering mechanism and the rate of dissolution.

These reactions, however, are complex and generally proceed through a series of reaction steps. The rate of weathering of silicates may vary considerably depending on the arrangement of the silicon tetrahedra in the mineral and on the nature of the cations.

\section{The Role of Weathering in Geochemical Processes in Oceanic and Global Systems}

As indicated in the stoichiometric equations given above, the rate of chemical weathering is important in determining the rate of $\mathrm{CO}_{2}$ consumption. Furthermore, the global weathering rate is most likely influenced by temperature and is proportional to total continental land area and the extent of its coverage with vegetation; the latter dependence results from $\mathrm{CO}_{2}$ production in soils, which is a consequence of plant respiration and the decay of organic matter as well as the release of complexforming ligands (dicarboxylic acids, hydroxycarboxylic acids, and phenols), i.e., anions that form soluble complexes with cations that originate from the lattice or form surface complexes with the surface of oxide minerals. Regionally, the extent of weathering is influenced by acid rain [Schnoor, 1990; Schnoor and Stumm, 1985].

It has been shown by Berner et al. [1983] and by Berner and Lasaga [1989] that silicate weathering is more important than carbonate mineral weathering as a longterm control on atmospheric $\mathrm{CO}_{2}$. The $\mathrm{HCO}_{3}^{-}$and $\mathrm{Ca}^{2+}$ ions produced by weathering of $\mathrm{CaCO}_{3}$,

$$
\mathrm{CaCO}_{3}+\mathrm{CO}_{2}+\mathrm{H}_{2} \mathrm{O}=\mathrm{Ca}^{2+}+2 \mathrm{HCO}_{3}^{-}
$$

precipitate in the ocean (through incorporation by marine organisms) as $\mathrm{CaCO}_{3}$. The $\mathrm{CO}_{2}$ consumed in carbonate weathering is released again upon formation of $\mathrm{CaCO}_{3}$ in the ocean (reversal of the reaction given above). Thus, globally, carbonate weathering results in no net loss of atmospheric $\mathrm{CO}_{2}$. The weathering of calcium silicates, e.g., equation ( $1 a)$ or, in a simplified way,

$$
\mathrm{CaSiO}_{3}+2 \mathrm{CO}_{2}+3 \mathrm{H}_{2} \mathrm{O}=\mathrm{Ca}^{2+}+2 \mathrm{HCO}_{3}^{-}+\mathrm{H}_{4} \mathrm{SiO}_{4}
$$

also produces $\mathrm{Ca}^{2+}$ and $\mathrm{HCO}_{3}^{-}$, which form $\mathrm{CaCO}_{3}$ in the sea, but only half of the $\mathrm{CO}_{2}$ consumed in the weathering is released and returned to the atmosphere upon $\mathrm{CaCO}_{3}$ formation. Thus silicate weathering results in a net loss of atmospheric $\mathrm{CO}_{2}$. Of course, ultimately, the cycle is completed by metamorphic and magmatic breakdown, deep in the Earth, of $\mathrm{CaCO}_{3}$ with the help of $\mathrm{SiO}_{2}$, a reaction that may be represented in a simplified way as $\mathrm{CaCO}_{3}+\mathrm{SiO}_{2}=\mathrm{CaSiO}_{3}+\mathrm{CO}_{2}$. Knowledge of the rate of dissolution of minerals is also necessary for the quantitative evaluation of geochemical processes in the oceanic system.

\section{Diffusion-Controlled Versus Surface-Controlled Mechanisms}

Among the theories proposed, essentially two main mechanisms can be distinguished; these are that the rate-determining step is a transport step (e.g., a transport of a reactant or a weathering product through a layer of the surface of the mineral) or that the dissolution reaction is controlled by a surface reaction. The rate equation corresponding to a transport-controlled reaction is known as the parabolic rate law when

$$
r=\frac{d C}{d t}=k_{p} t^{-1 / 2}\left[\mathrm{M} \mathrm{s}^{-1}\right]
$$

where $k_{p}$ is the reaction rate constant $\left[\mathrm{M} \mathrm{s}^{-1 / 2}\right]$. (The symbol $\mathrm{M}^{\mathrm{M}}$ means $\mathrm{mol} \mathrm{dm}^{-3}$.) By integration the concentration in solution, $C[\mathrm{M}]$, increases with the square root of time: 


$$
C=C_{0}+2 k_{p} t^{1 / 2}
$$

Alternatively, if the reactions at the surface are slow in comparison with diffusion or other reaction steps, the dissolution processes are controlled by the processes at the surface. In this case the concentrations of solutes adjacent to the surface will be the same as in the bulk solution. The dissolution kinetics follows a zero-order rate law if the steady state conditions at the surface prevail:

$$
r=\frac{d \mathrm{C}}{d t}=k a\left[\mathrm{M} \mathrm{s}^{-1}\right]
$$

where the dissolution rate $r\left[\mathrm{M} \mathrm{s}^{-1}\right]$ is proportional to the surface area of the mineral, $a\left[\mathrm{~m}^{2}\right] ; k$ is the reaction rate constant $\left[\mathrm{M} \mathrm{m}^{-2} \mathrm{~s}^{-1}\right]$.

Figure $1 a$ shows examples of the results obtained on the dissolution of $\delta-\mathrm{Al}_{2} \mathrm{O}_{3}$. In batch experiments where $p \mathrm{H}$ is kept constant with an automatic titrator, the concentration of $\mathrm{Al}(\mathrm{III})(\mathrm{aq})$ is plotted as a function of time. The linear dissolution kinetics observed for every $p \mathrm{H}$ is compatible with a process whose rate is controlled by a surface reaction. The rate of dissolution is obtained from the slope of the plots.

Figure $1 b$ gives results by Schott and Berner [1985] on the dissolution rate of iron-free pyroxenes and olivines, as measured by the silica release.

The parabolic rate law has been proposed by numerous authors to describe their experimental results [Correns and von Engelhardt, 1938; Wollast. 1967; Helgeson, 1971; Luce et al., 1972; Paces, 1973; Busenberg and Clemency, 1976; Chou and Wollast, 1984; Holdren and Speyer. 1985]. An apparent parabolic rate law may be obtained if preferential dissolution of fine particles or of highly active sites at the surface of the mineral occurs during the initial stages of the experiments [Holdren and Berner, 1979]. Also, in many cases presented in the literature, the concentrations of the dissolved reactants reach the saturation state with respect to new mineral phases and induce precipitation of secondary minerals. This process limits the increase in concentration of the precipitating elements, which in turn yields an apparent incongruent reaction and pseudoparabolic kinetics. It is thus imperative to examine carefully the various possibilities before concluding that the reaction kinetics follow a parabolic rate law due to a diffusion mechanism.

We will not review here the controversy concerning the existence of a leached layer at the surface of the dissolving mineral [Petrovic et al., 1976; Holdren and Berner, 1979; Schott et al., 1981; Berner and Schott, 1982]. More recent studies on surface layers (including nuclear resonance profiling) have been provided by Eggleton et al. [1987], Petit et al. [1987], Schott and Petit [1987], and Casey et al. [1989]. Even if the dissolution reaction of a mineral is initially incongruent, it is often a surface reaction which will eventually control the overall dissolution rate of this mineral. This has been shown by Chou and Wollast [1984] and Schnoor [1990] and based on earlier reaction modeling by Luce et al. [1972] and Paces [1973] and will
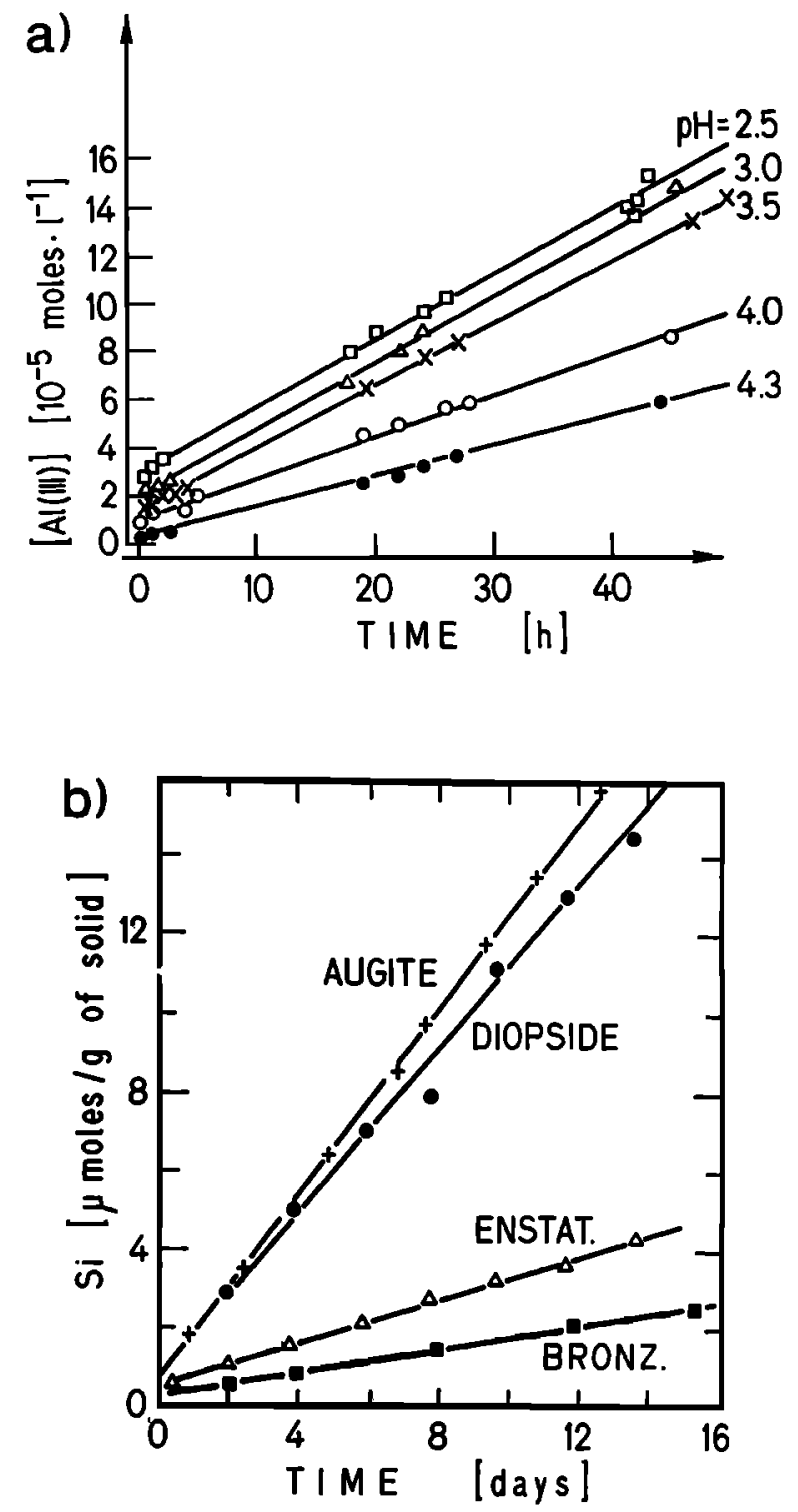

Figure 1. (a) Linear dissolution kinetics observed for the dissolution of $\delta-\mathrm{Al}_{2} \mathrm{O}_{3}$, representative of processes whose rates are controlled by a surface reaction and not by a transport step (data from Furrer and Stumm [1986]. (b) Linear dissolution kinetics of frame silicates. Minerals used were pyroxenes and olivines; their essential structural feature is the linkage of $\mathrm{SiO}_{4}$ tetrahedra, laterally linked by bivalent cations $\left(\mathrm{Mg}^{2+}, \mathrm{Fe}^{2+}, \mathrm{Ca}^{2+}\right)$. Plotted are amounts of silica released versus time for the dissolution of etched enstatite, bronzite $\left(p_{\mathrm{O}_{2}}=0\right)$, diopside, and augite at $\mathrm{pH} 6$ ( $T=20^{\circ} \mathrm{C}$ for bronzite; $T=50^{\circ} \mathrm{C}$ for the other minerals) [from Schott and Berner, 1985].

be elaborated in more detail by R. Wollast and W. Stumm (work in preparation, 1990). We may conclude that in natural environments the steady state surface-controlled dissolution step is the main process controlling the weathering of most oxides and silicates. It is thus of primary importance to identify the several variables affecting this rate and to elucidate their role in the weathering mechanism. 


\section{A GENERAL RATE LAW FOR SURFACE- CONTROLLED DISSOLUTION}

We would like to provide the reader first with a qualitative understanding of the subject of dissolution kinetics. In the dissolution reaction of an oxide mineral, the coordinative environment of the metal changes; for example, in dissolving an aluminum oxide layer, the $\mathrm{Al}^{3+}$ in the crystalline lattice exchanges its $\mathrm{O}^{2}$ ligand for $\mathrm{H}_{2} \mathrm{O}$ or another ligand $\mathrm{L}$. The most important reactants participating in the dissolution of a solid mineral are $\mathrm{H}_{2} \mathrm{O}$, $\mathrm{H}^{+}, \mathrm{OH}^{-}$, ligands (surface complex building), and reductants and oxidants (in the case of reducible or oxidizable minerals).

Thus the reaction occurs schematically in two sequences:

$$
\begin{aligned}
& \text { surface sites + reactants }\left(\mathrm{H}^{+}, \mathrm{OH}^{-} \text {, or ligands }\right) \\
& \stackrel{\text { fast }}{\rightarrow} \text { surface species }
\end{aligned}
$$

$$
\text { surface species } \underset{\text { detachment of } \mathrm{Me}}{\longrightarrow} \mathrm{Me}(\mathrm{aq})
$$

where Me stands for metal. Although each sequence may consist of a series of smaller reaction steps, the rate law of surface-controlled dissolution is based on the idea (1) that the attachment of reactants to the surface sites is fast and (2) that the subsequent detachment of the metal species from the surface of the crystalline lattice into the solution is slow and thus rate limiting. In the first sequence the dissolution reaction is initiated by the surface coordination with $\mathrm{H}^{+}, \mathrm{OH}^{-}$, and ligands which polarize, weaken, and tend to break the metal-oxygen bonds in the lattice of the surface. Since reaction (7) is rate limiting, the rate law on the dissolution reaction will show a dependence on the concentration (activity) of the particular surface species, $C_{j}$ [ $\mathrm{mol} \mathrm{m}^{-2}$ ]:

$$
\text { dissolution rate } \propto \text { [surface species] }
$$

We reach the same conclusion (equation (8a)) if we treat the reaction sequence according to the activated complex theory (ACT), often also called the transition state theory. The particular surface species that has formed from the interaction of $\mathrm{H}^{+}, \mathrm{OH}^{-}$, or ligands with surface sites is the precursor of the activated complex (Figure 2):

$$
\text { dissolution rate } \propto \text { (precursor of the activated complex }
$$

The surface concentration of the particular surface species, $C_{j}$, corresponds to the concentration of the precursor of the activated complex. Note that we use braces and brackets to indicate surface concentrations $\left[\mathrm{mol} \mathrm{m}^{-2}\right]$ and solute concentrations [M], respectively. Equation (8) can usually be determined from the knowledge of the number of surface sites and the extent of surface protonation or surface deprotonation or the surface concentration of ligands. Surface protonation or deprotonation can be measured from alkalimetric or acidimetric surface titrations, and ligands bound to the surface sites can be determined analytically, from the change in the concentration of ligands in solution. Most generally, the dissolution rate $R\left[\mathrm{~mol} \mathrm{~m}^{-2} \mathrm{~s}^{-1}\right.$ ] is, in line with (8a) and (8b), proportional to the surface concentration (activity) of the precursor species $\left[\mathrm{mol} \mathrm{m}^{-2}\right]$ :

$$
R=k C_{j}
$$

$C_{j}$ is proportional to the density of surface sites, $S$, the mole fraction $\chi_{a}$ of these surface sites which are dissolution active, and the probability $P_{j}$ of finding a site in the suitable coordinative arrangement of the precursor complex:

$$
C_{j}=\chi_{a} P_{j} S
$$

Thus the dissolution rate can be generalized [Wieland et al., 1988] into

$$
R=k \chi_{a} P_{j} S
$$

where

$R \quad$ dissolution rate $\left[\mathrm{mol} \mathrm{m}^{-2} \mathrm{~s}^{-1}\right]$;

$k \quad$ appropriate rate constant $\left[\mathrm{s}^{-1}\right]$;

$S$ surface concentration of sites $\left[\mathrm{mol} \mathrm{m}^{-2}\right]$;

$\chi_{a} \quad$ mole fraction of dissolution active sites;

$P_{j} \quad$ probability of finding a specific site in the coordinative arrangement of the precursor complex.

We shall provide more information on the chemistry of the mineral-water interface to describe $\chi_{a}$ and $P_{j}$ and to interpret $k$. But it may be convenient first to give rate laws for the ligand-promoted and the proton-promoted dissolution rate.

The ligand-promoted dissolution rate $R_{\mathrm{L}}$ is proportional to the density of sites occupied by adsorbed (surface bound) ligands, $P_{j} \propto\{>\mathrm{ML}\}$; thus

$$
R_{L}=k_{L}^{\prime}(>\mathrm{ML}]
$$

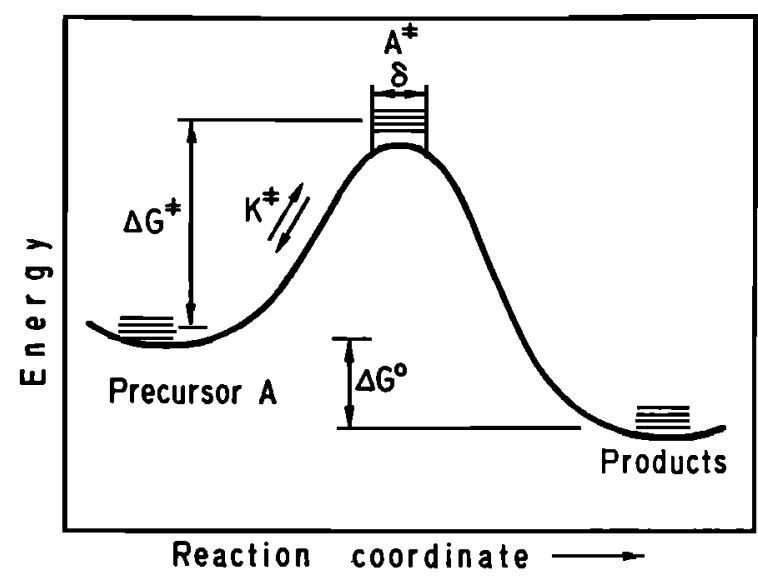

Figure 2. Activated complex theory for the surface-controlled dissolution of a mineral far from equilibrium. $A$ is the precursor, i.e., a surface site that can be activated to $A^{\ddagger}$. 
The acid-promoted (proton-promoted) dissolution rate $R_{\mathrm{H}}$ is proportional to the density of protonated sites to the power of $j, P_{j} \propto\left\{>\mathrm{MOH}_{2}^{+}\right\}^{j}$ :

$$
R_{\mathrm{H}}=k_{\mathrm{H}}^{\prime}\left\{>\mathrm{MOH}_{2}^{+}\right\}^{j}=k^{\prime}\left(C_{\mathrm{H}}^{s}\right)^{j}
$$

where $[>\mathrm{ML}$ ] is the concentration of the surface complex of the ligand $\mathrm{L}, C_{\mathrm{L}}^{\mathrm{s}}\left[\mathrm{mol} \mathrm{m}^{-2}\right] ;\left\{>\mathrm{MOH}_{2}^{+}\right\}$is the concentration of protonated surface hydroxo group, $C_{\mathrm{H}}^{s}=C_{\mathrm{H}}^{s}[\mathrm{~mol}$ $\left.\mathrm{m}^{-2}\right]$, which is equivalent to the surface protonation; and $j$ is the exponent, which in ideal cases corresponds to the oxidation state of the central metal ion in the crystalline lattice (e.g., $j=3$ for $\mathrm{Al}$ and $\mathrm{Fe}(\mathrm{III}) ; j=2$ for $\mathrm{Be}(\mathrm{II})$ and $\mathrm{Mg}(\mathrm{II}) ; j=4$ for $\mathrm{Si}(\mathrm{IV}))$.

The density of surface sites occupied with $\mathrm{L},[>\mathrm{ML}]$, or with protons, $\left[>\mathrm{MOH}_{2}^{+}\right]$, is related to the concentration of $\mathrm{L}$ in solution, $[\mathrm{L}]$, by a complex formation equilibrium (adsorption equilibrium) or by a surface protonation equilibrium, respectively. The rate laws should preferably be written in terms of surface species. Since the concentration of surface species at equilibrium is usually not linearly dependent on the concentration of the species in solution, fractional order dependence of solution rates on [L] and $\left[\mathrm{H}^{+}\right]$result if rate laws are formulated in terms of solutes:

$$
R_{\mathrm{L}} \propto[\mathrm{L}]^{m} \text { or } R_{\mathrm{H}} \propto\left[\mathrm{H}^{+}\right]^{n}
$$

where $m<1$ and $n<1$.

\section{THE MINERAL-WATER INTERFACE}

The dissolution of a mineral is a sum of chemical and physical reaction steps. In the case of a metal oxide, the $\mathrm{Me}^{n+}$ in the crystal lattice exchanges its $\mathrm{O}^{2-}$ ligands for water or another ligand $\mathrm{L}$ according to the following scheme [Valverde and Wagner, 1976]

$$
\begin{aligned}
\mathrm{Me}^{n+} \text { (mineral) }+\mathrm{H}_{2} \mathrm{O} & \rightleftarrows \mathrm{Me}(\mathrm{aq})^{n+} \\
\mathrm{Me}^{n+}(\text { mineral })+\mathrm{L}^{m-}+\mathrm{H}_{2} \mathrm{O} & \rightleftarrows \mathrm{Me}(\mathrm{aq})^{(n-m)} \\
\mathrm{O}^{2-} \text { (mineral) }+2 \mathrm{H}^{+}(\mathrm{aq}) & \rightleftarrows \mathrm{H}_{2} \mathrm{O}
\end{aligned}
$$

Each one of these coupled partial reactions consists of smaller reaction steps. Me stands for metals. The single ion hydration energies for $\mathrm{Me}$ (II) and $\mathrm{Me}$ (III) cations are of the order of 2000 and $4000 \mathrm{~kJ} \mathrm{~mol}^{-1}$, respectively [Burgess, 1978]. These energies preclude mechanisms in which cations and anions $\left(\mathrm{OH}^{-}, \mathrm{O}^{2-}\right)$ dissolve independently [Wehrli, 1989]. In order to appreciate the chemical reactions that may assist the detachment of lattice constituents into solution, we will review the surface chemistry of the hydrous oxide-water interface [Stumm et al., 1970, 1976, 1980, 1987; Sposito, 1983, 1984; Schindler and Stumm, 1987].

\section{Surface Coordination as a Complement to the Electric Double Layer Theory}

For the last decades the electric double layer model has generally been the conceptual framework for interpreting many surface chemical phenomena. But the fundamental chemical interaction of solutes with natural surfaces occurs through the formation of coordinative bonds. Thus specific chemical factors need to be considered in addition to the theory of the electric double layer to explain many phenomena in natural systems and to derive rate laws for geochemical processes [Schindler and Stumm, 1987].

The interaction of a solute with a surface, be it in terms of adsorption or surface complexation (i.e., coordinative, often covalent binding of a solute with surface constituents of the mineral surface), requires a characterization of the physical and chemical properties of the solvent (electrolyte), the solute, and the sorbent (Figure 3). While the surface in the electric double layer model is assumed to be a structureless continuum which interacts with the solution primarily by its electric charge, the basic concept in the surface coordination model is the surface functional groups formed on all natural inorganic and organic hydrous solids; the surface groups present depend on the building constituents of the minerals. They may be, for example, $-\mathrm{SH}$ (sulfides), $-\mathrm{S}-\mathrm{S}$ (pyrite), or $-\mathrm{CO}_{2} \mathrm{OH}$ (carbonates). Oxides and silicates contain, above all, surface $\mathrm{OH}$ groups. Our discussion will concentrate on these (see Figure 3); they are responsible for the surface reactivity (and mechanism of specific adsorption, the term used whenever adsorption occurs by interactions that are not solely electrostatic). Geometrical considerations and chemical measurements indicate an average surface density of five (typical range 2-12) hydroxyls per square nanometer of an oxide mineral. The various surface hydroxyls formed may not be structurally and chemically fully equivalent, but to facilitate the formulation of thermodynamic equilibria, one usually considers the chemical reactions of "a" surface hydroxyl group S-OH. These functional groups contain the same donor atoms as found in functional groups of soluble ligands; for example, the surface hydroxyl group on a hydrous oxide or on an organic solid has donor properties similar to the corresponding counterparts in dissolved molecules such as hydroxide ions and carboxylates. We need to consider, however, that the functional groups are bound into a solid framework and their reactivity is, in essence, a cooperative property [Sposito, 1984]. In a mean field approach, a hydrous oxide particle can be treated statistically as a polymeric oxoacid (or base) which tends to undergo protolysis and to coordinate with metal ions and ligands. An inner-sphere complex, as indicated in Figure 3, involves a chemical (often a covalent) bond; no $\mathrm{H}_{2} \mathrm{O}$ molecule is interposed between the functional group or the central ion and the bond species. Outer-sphere surface complexes involve electrostatic binding mechanisms; at least one $\mathrm{H}_{2} \mathrm{O}$ molecule is interposed between the complex partners. The reactivity of the surface (i.e., its tendency to dissolve) depends on the 


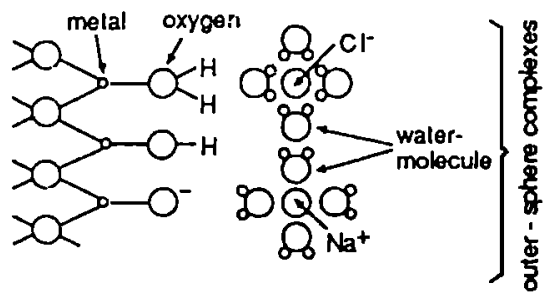

a)<smiles>COCCOCCO</smiles><smiles>CC1(C)OC2OC3OC2CC1O3</smiles>

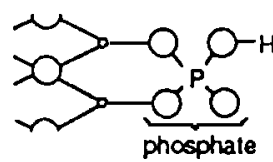<smiles>CC1(O)CCCCC1F</smiles><smiles>CC(C)OC(=O)C(=O)OC(C)C</smiles>

Figure 3. An oxide surface (Figure $3 a$ ) covered in the presence of water with amphoteric surface hydroxyl groups, $>\mathrm{M}-\mathrm{OH}$, can be looked at as a polymeric oxyacid or base. The surface $\mathrm{OH}$ group has a complex-forming $O$ donor atom that coordinates with $\mathrm{H}^{+}$(Figure $3 b$ ) and metal ions (Figure $3 c$ ). The $\mathrm{H}^{+}$bound to the surface can be determined experimentally by alkalimetric titration of an oxide suspension in a given electrolyte solution; ZPC is the point of zero proton condition ("zero point of charge"). The underlying central ion in the surface layer of the oxide acting

type of surface species present. For example, an innersphere complex such as that shown for oxalate facilitates the detachment of a central metal ion and enhances the dissolution. Similarly, surface protonation tends to increase the dissolution rate. On the other hand, a surfacecoordinated metal ion (e.g., $\mathrm{Cu}^{2+}$ or $\mathrm{Al}^{3+}$ ) may block a surface group and thus retard dissolution. An outer-sphere surface complex such as $\mathrm{SO}_{4}^{2-}$ adsorbed to an $\mathrm{Al}(\mathrm{III})$ (hydr)oxide has no effect on the dissolution rate.

The ideas developed here are largely based on the concept of the (hydr)oxide interface; the ideas apply equally well to silicates. Somewhat modified concepts for the surface chemistry of carbonate, phosphate, sulfide, and disulfide minerals have to be developed.

Energies of interaction of surface functional groups include electrostatic and chemical contributions. The selectivity of interaction of hydrous oxides and silicates with many solute species (metal ions and ligands) can be accounted for only by considering specific chemical interactions.
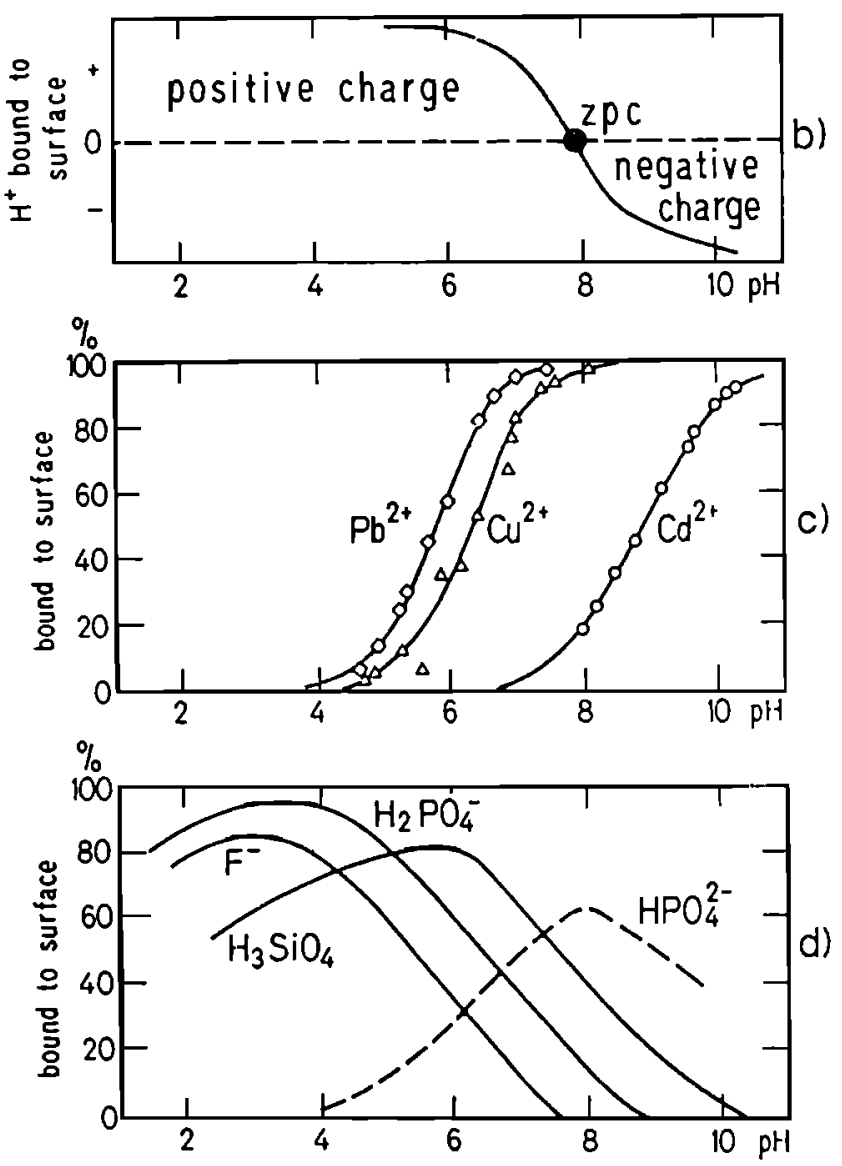

as a Lewis acid can exchange its structural $\mathrm{OH}$ ions against other ligands (anions or weak acids) (Figure 3d). The extent of surface coordination and its $p \mathrm{H}$ dependence can be quantified by mass action equations and can be explained by considering the affinity of the surface sites for metal ion or ligand and the $p H$ dependence of the activity of surface sites and ligands. The tendency to form surface complexes may be compared with the tendency to form corresponding solute complexes (Figure $3 a$ is modified from Sposito [1984]).

\section{The Coordination Chemistry of the Oxide-Water Interface}

The presence of two lone electron pairs and a dissociatable hydrogen ion at surface hydroxyl groups $\mathrm{S}-\mathrm{OH}$ (we will also use $>\mathrm{M}-\mathrm{OH}$ if the control ion is a metal ion) indicates that these groups are ampholytes (i.e., they can act as acids or bases). Adsorption of $\mathrm{H}^{+}$and $\mathrm{OH}^{-}$ions is thus based on protonation and deprotonation of surface hydroxyls:

$$
\begin{aligned}
\mathrm{S}-\mathrm{OH}+\mathrm{H}^{+} & \rightleftarrows \mathrm{S}-\mathrm{OH}_{2}^{+} \\
\mathrm{S}-\mathrm{OH}\left(+\mathrm{OH}^{-}\right) & \rightleftarrows \mathrm{S}-\mathrm{O}^{-}+\mathrm{H}^{+}\left(+\mathrm{H}_{2} \mathrm{O}\right)
\end{aligned}
$$

Deprotonated surface hydroxyls exhibit Lewis base behavior; that is, the adsorption of metal ions is therefore understood as competitive complex formation involving one or two surface hydroxyls.

$$
\begin{aligned}
\mathrm{S}-\mathrm{OH}+\mathrm{M}^{2+} & \rightleftarrows \mathrm{S}-\mathrm{OM}^{(z-1)+}+\mathrm{H}^{+} \\
2 \mathrm{~S}-\mathrm{OH}+\mathrm{M}^{2+} & \rightleftarrows(\mathrm{S}-\mathrm{O})_{2} \mathrm{M}^{(z-2)+}+2 \mathrm{H}^{+}
\end{aligned}
$$


The central ion, acting as a Lewis acid (i.e., a metal center that can bind covalently with a ligand), can exchange its structural $\mathrm{OH}^{-}$ions against other ligands (complex-forming anions or weak acids; ligand exchange) [Sigg and Stumm, 1981]:

$$
\begin{aligned}
\mathrm{S}-\mathrm{OH}+\mathrm{L} & \rightleftarrows \mathrm{S}-\mathrm{L}^{+}+\mathrm{OH}^{-} \\
2 \mathrm{~S}-\mathrm{OH}+\mathrm{L} & \rightleftarrows \mathrm{S}_{2} \mathrm{~L}^{2+}+2 \mathrm{OH}^{-}
\end{aligned}
$$

For the case where $\mathrm{L}$ is a polydentate ligand, under certain circumstances ternary surface complexes may be formed:

$$
\mathrm{S}-\mathrm{OH}+\mathrm{L}+\mathrm{M}^{2+} \rightleftarrows \mathrm{S}-\mathrm{L}-\mathrm{M}^{(2-1)+}+\mathrm{OH}^{-}
$$

\section{Equilibrium Constants}

The concept of surface complexation permits us to handle adsorption equilibria in the same way as equilibria in solutions. Hence uptake and release of $\mathrm{H}^{+}$ions in solutions of constant ionic strength (equations (15) and (16)) can be described by the acidity constants

$$
\begin{gathered}
K_{a 1}^{s}=\frac{\{\mathrm{SOH}\}\left[\mathrm{H}^{+}\right]}{\left\{\mathrm{SOH}_{2}^{+}\right\}}\left(\mathrm{mol} \mathrm{dm}^{-3}\right) \\
K_{a 2}^{s}=\frac{\left\{\mathrm{SO}^{-}\right\}\left[\mathrm{H}^{+}\right]}{[\mathrm{SOH}]}\left(\mathrm{mol} \mathrm{dm}^{-3}\right)
\end{gathered}
$$

where braces denote the concentrations of surface species in moles per square meter of adsorbing solid. (Frequently, the concentration of surface species is given in moles per kilogram of adsorbing solids. Conversion into surface densities is easily accomplished if the specific surface area of the adsorbing solid is known.)

The quotients $K_{a 1}^{s}, K_{a 2}^{s}$, introduced above, and similar expressions related to the metal complexation and to ligand exchange are experimentally accessible quantities. They have the rank of conditional stability constants whose values (at constant temperature, pressure, and ionic strength) are, because of the cooperative properties of the functional groups, dependent on the prevailing surface coverage. A frequently encountered empirical relation is

$$
\begin{gathered}
K^{s}(\mathrm{X})=K_{(\mathrm{int})}^{s}(\mathrm{X}) \exp (-\alpha\{\mathrm{X}]) \\
\log K^{s}(\mathrm{X})=\log K_{(\mathrm{int})}^{s}(\mathrm{X})-\frac{\alpha}{\ln (10)}[\mathrm{X}\}
\end{gathered}
$$

$K^{s}(\mathrm{X})$ is the conditional stability constant of the surface species $X, K_{\text {(int) }}^{s}$ is the intrinsic constant, and $\alpha$ is an empirical constant whose value is dependent on the system under consideration. Equation (25) demonstrates the possibility of evaluating intrinsic constants by simple linear extrapolation of the experimentally available conditional constant. When the total particle charge $\sigma$ is small, it is proportional to the inner potential $\Psi_{s}$ at the surface, and the proportionality constant $C$ is the capacitance of the flat electric double layer (in farads per square meter).

$$
\sigma=C \Psi_{s}
$$

In the so-called constant capacity model, (24) could also be written as

$$
\begin{aligned}
K^{s}(\mathrm{X}) & =K_{(\mathrm{int})}^{s}(\mathrm{X}) \exp \left(F \psi_{s} / R T\right) \\
& =K_{(\mathrm{int})}^{s}(\mathrm{X}) \exp \left(-F^{2} \sigma / C R T\right)
\end{aligned}
$$

where $F, R$, and $T$ represent the Faraday constant, the molar gas constant, and the temperature, respectively. Sposito [1983] has shown that (27) can be derived from a general lattice statistical mean field model which is mathematically equivalent to the Bragg-Williams approximation. The two model parameters, the "intrinsic" constant $K_{a 1(\mathrm{int})}^{s}$ at zero surface charge and the integral capacitance $C$ of the electric double layer, can be determined from titration curves. In the absence of other specifically adsorbing species the surface charge due to bound protons may be approximated by

$$
\sigma \approx\left\{>\mathrm{MOH}_{2}^{+}\right\}
$$

Solving (25) for $\left[\mathrm{H}^{+}\right]$and using (27) and (28) yields the well-known Frumkin-Fowler-Guggenheim (FFG) isotherm [Frumkin, 1925; Fowler and Guggenheim, 1939]:

$$
\begin{aligned}
{\left[\mathrm{H}^{+}\right]=K_{a 1 \text { (int) }}^{s} \cdot \frac{\left\{>\mathrm{MOH}_{2}^{+}\right\}}{S-\left\{>\mathrm{MOH}_{2}^{+}\right\}} } & \cdot \exp \left(F^{2} \cdot\left\{>\mathrm{MOH}_{2}^{+}\right\} / C R T\right)
\end{aligned}
$$

If we define the mole fraction $\chi_{H}$ and the interaction en$\operatorname{ergy} w\left[\mathrm{~J} \mathrm{~mol}^{-1}\right]$ as

$$
\begin{gathered}
\chi_{\mathrm{H}}=\left\{>\mathrm{MOH}_{2}^{+}\right] / \mathrm{S} \\
w=F^{2} \cdot S / 2 C
\end{gathered}
$$

then (29) takes the more familiar form

$$
\left[\mathrm{H}^{+}\right]=K_{a 1 \text { (int) }}^{s} \cdot \frac{\chi_{\mathrm{H}}}{1-\chi_{\mathrm{H}}} \exp \left(2 w \cdot \chi_{\mathrm{H}} / R T\right)
$$

In Figure $4 a$ the FFG equation (equation (29)) is applied to the protonation equilibria at different oxide surfaces. The parameters $K_{a 1(\mathrm{int})}^{s}$ and $C$ were determined from published titration curves using a typical crystallographic site density $S=1.67 \times 10^{-5} \mathrm{~mol} \mathrm{~m}^{-2}$ (corresponding to 10 sites per square nanometer).

As Figure $4 a$ indicates and as has been shown by Wieland et al. [1988], the Frumkin equation (29) is able to represent different protonation data over a wide range of $p \mathrm{H}$. Generally, the surface protonation increases only slightly with decreasing $p \mathrm{H}$. This nonideal (or "nonLangmuirian") behavior is due to electrostatic interactions at the oxide-water interface which lead to an inhibition of the proton uptake at the progressively more positively charged surface.

Anderson et al. [1976] and, recently, Harding and Healy [1985] and Fokking [1987] have shown that the same protonation curve describes various particle surfaces if $p \mathrm{H}$ is normalized, i.e., the difference

$$
\Delta p \mathrm{H}=p \mathrm{H}_{\mathrm{ZPC}}-p \mathrm{H}
$$



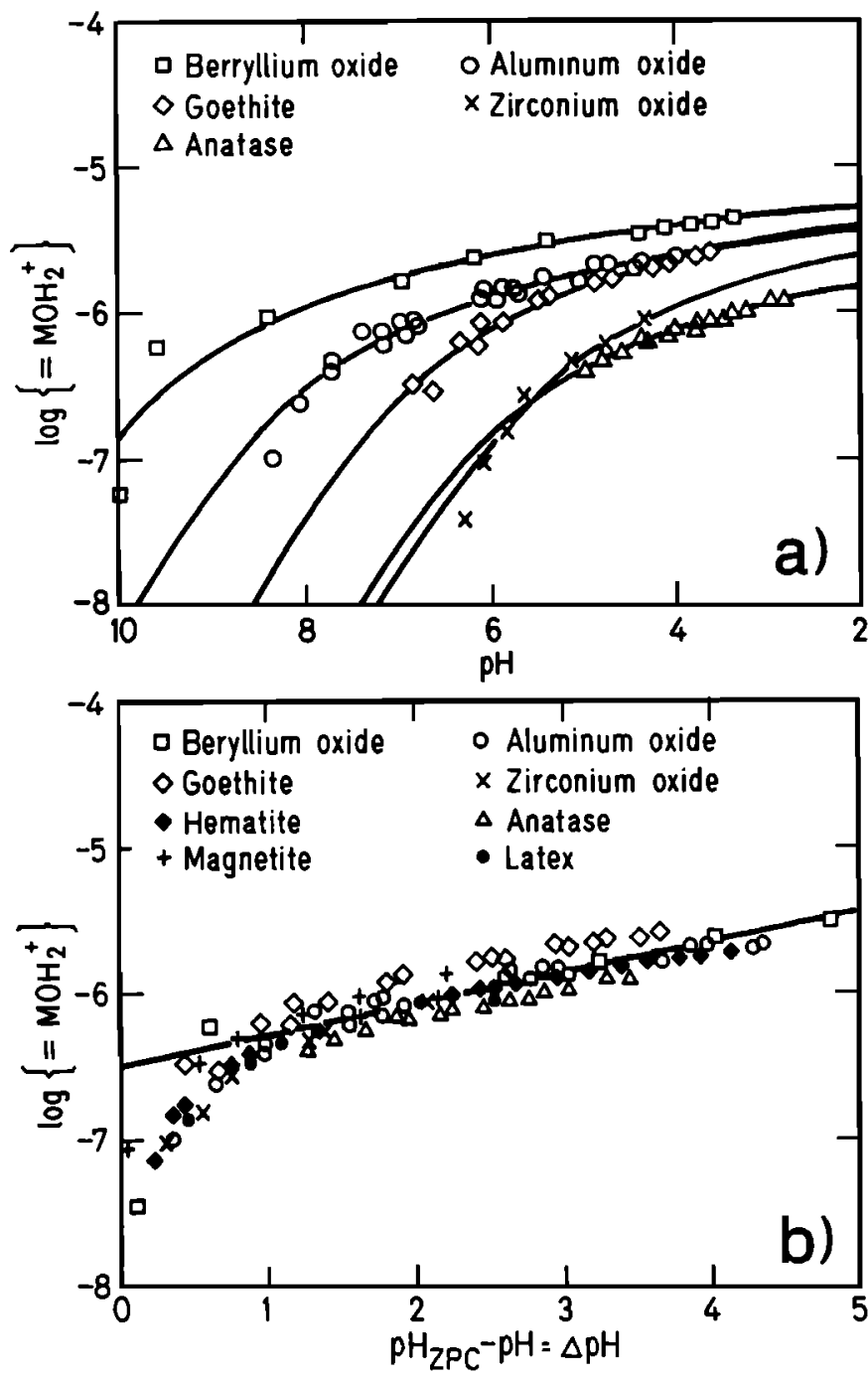

Figure 4. Surface protonation isotherms. Points represent experimental data from titration curves at ionic strength $I=0.1$ (hematite, $I=0.2$ ). The concentration of protonated sites $\left[=\mathrm{MOH}_{2}^{+}\right]$is given in moles per square meter. BET surface data were used to calculate the surface concentrations. (a) Frumkin isotherms (equation (29)). (b) Surface concentration as a function of $p \mathrm{H}_{\mathrm{ZPC}}-p \mathrm{H}=\Delta p \mathrm{H}$. The adsorption isotherm at $\Delta p H>1$ can be interpreted as a Freundlich master isotherm [from Wieland et al., 1988].

is plotted as a master variable. The index ZPC denotes the zero point of charge [Stumm and Morgan, 1981]. This concept is applied in Figure $4 b$ to seven different oxides and one latex sample. In the range $\Delta p \mathrm{H}>1$ a straight line fits all the experimental data within a factor of 2 . Therefore a suitable geochemical approximation can be given by a Freundlich master isotherm (for the "adsorption" of $\mathrm{H}^{+}$ ions) of the form

$$
\left\{>\mathrm{MOH}_{2}^{+}\right\}=\frac{K_{F}}{\left[\mathrm{H}^{+}\right]_{\mathrm{ZPC}}^{m}} \cdot\left[\mathrm{H}^{+}\right]^{m}
$$

with the parameters $p K_{F}=-6.51$ and $m=0.21$.

The consequence of proton binding by different hydrous oxides as shown by the master curve of Figure $4 b$ (where surface protonation is plotted as a function of $p \mathrm{H}_{\mathrm{ZPC}}-p \mathrm{H}$ ) illustrates that the proton binding is mostly independent of the nature of the oxide. The oxide-specific properties are reflected in the zero point of charge where, for example, $\mathrm{Al}_{2} \mathrm{O}_{3}$ has a larger $\mathrm{H}^{+}$affinity (higher $p \mathrm{H}_{\mathrm{ZPC}}$ ) than $\mathrm{ZrO}_{2}$ [Lyklema, 1987].

\section{Surface Complex Formation With Ligands}

As with metal ions, the extent of adsorption of anions and weak acids is strongly governed by the $p \mathrm{H}$ of the solution. Since adsorption of anions is coupled with a release of $\mathrm{OH}^{-}$ions (equation (19)), adsorption is favored by low $p \mathrm{H}$ values (Figure $3 d$ ). The tendency to form surface complexes is correlated with the tendency to form complexes in solution [Sigg and Stumm, 1981]. This can be exemplified by comparing the surface reaction

$$
>\mathrm{FeOH}+\mathrm{H}_{2} \mathrm{~A} \rightleftarrows>\mathrm{FeHA}+\mathrm{H}_{2} \mathrm{O}{ }^{*} K_{1}^{s}
$$

with the corresponding reaction in solution

$$
\mathrm{FeOH}^{2+}+\mathrm{H}_{2} \mathrm{~A} \rightleftarrows \mathrm{FeHA}^{2+}+\mathrm{H}_{2} \mathrm{O} \quad{ }^{*} K_{1}
$$

Besides having this support from thermodynamics, the proposed model is in agreement with investigations on the kinetics of adsorption of acetic acid (HAc) on silicaalumina surfaces [Ikeda et al., 1982] that demonstrate that the important step consists of

$$
>\mathrm{Al}-\mathrm{OH}_{2}^{+}+\mathrm{Ac}^{-} \rightleftarrows>\mathrm{Al}-\mathrm{Ac}+\mathrm{H}_{2} \mathrm{O}
$$

\section{Surface Species, Their Structural Identity and Surface} Reactivity

For many years, the specific reactions postulated above were mainly the offspring of classical equilibrium analysis. There is now increasing support from spectroscopy [von Zelewsky and Bemtgen, 1982; Motschi, 1987; Hayes et al., 1987] in elucidating the structure of surface complexes.

Structural Identity Unfortunately, spectroscopic methods are seldom sufficiently sensitive to reveal the structure of surface complexes. Motschi [1987] used electron spin resonance spectroscopy to study $\mathrm{Cu}(\mathrm{II})$ surface complexes. Additional studies were carried out with electron nuclear double resonance spectroscopy (ENDOR) and electron spin echo envelope modulation (ESEEM) in order to elucidate structural aspects of surface-bound $\mathrm{Cu}(\mathrm{II})$, of ternary copper complexes (in which coordinated water is replaced by ligands), and of vanadyl ions on $\delta-\mathrm{Al}_{2} \mathrm{O}_{3}$. Application of ENDOR spectroscopy allows the resolution of weak interactions between the unpaired electron and nuclei within a distance of about $5 \AA$. From these socalled hyperfine data, structural parameters can be derived, e.g., bond distances of the paramagnetic center to the coupling nuclei or ligands. In the ENDOR spectrum of adsorbed $\mathrm{VO}^{2+}$ on $\delta-\mathrm{Al}_{2} \mathrm{O}_{3}$, signals caused by the coupling with the surface Lewis center $\left({ }^{27} \mathrm{Al}\right)$ are more strongly split than is calculated from molecular modeling. The existence of an inner-sphere coordination between the hydrated oxide and the metal is confirmed experimentally [Motschi. 1987]. 
Similarly, studies by Zeltner et al. [1986] with cylindrical internal reflection Fourier transform infrared spectroscopy suggest that salicylate adsorbs on goethite by forming a chelate structure in which each salicylate ion replaces two hydroxyls attached to a single ion atom at the surface.

Direct in situ $\mathrm{X}$ ray (from synchroton radiation) absorption measurements (EXAFS) [Hayes et al., 1987; Brown et al., 1989] permit the determination of the distances of adsorbed species to neighboring ions and to central ions on oxide surfaces in the presence of water. Such investigations showed, for example, that selenite is innerspherically and selenate is outer-spherically bound to the central Fe(III) ions of a goethite surface. It was also shown by this technique that $\mathrm{Pb}$ (II) is inner-spherically bound to $\delta-\mathrm{Al}_{2} \mathrm{O}_{3}$ [Chisholm-Brause et al., 1989].

Surface Reactivity The coordinative interactions taking place on the surface of minerals are of importance not only for the regulation of the composition of natural waters but also for the rates of processes that occur at mineral surfaces, such as precipitation (heterogeneous nucleation) and dissolution of mineral phases, of significance also in the formation of secondary minerals (soils and sediments) and in the corrosion of metals and their inhibition.

As Figure 5 illustrates schematically, a high degree of surface protonation of the surface ligands accelerates the dissolution because it leads to highly polarized interatomic bonds in the immediate proximity of the surface central ions and thus facilitates the detachment of a cationic surface group into the solution. Similarly, binding of $\mathrm{OH}^{-}$to the surface groups (which experimentally cannot be distinguished from deprotonation of the surface ligands $\left.-\mathrm{SO}(\mathrm{OH}) \rightarrow-\mathrm{SO}^{-}\right)$occurring at higher $p \mathrm{H}$ values facilitates the detachment of an anionic surface group into the solution.
Ligands that form surface complexes by ligand exchange with surface hydroxyl groups bring negative charge into the coordination sphere of the Lewis acid center of the hydrous oxide surface and can polarize the critical Me-oxygen bonds, thus enabling the detachment of the central metal ion into the adjacent solution. Most effective in enhancing the dissolution rate are bidentate ligands that form mononuclear complexes. The same ligands that form surface complexes usually also form complexes with these ions (e.g., $\mathrm{Al}(\mathrm{III}), \mathrm{Fe}$ (III), $\mathrm{Mg}(\mathrm{II})$ ) in solution and thus increase the solubility and, in turn, the activity gradient at the mineral solution interface. This enhancement of the solubility alone, however, has no effect on the dissolution rate if the dissolution is surface controlled.

Blocking of surface functional groups by cations, e.g., $\mathrm{VO}^{2+}, \mathrm{Cr}$ (III), and $\mathrm{Al}(\mathrm{III})$, tends to retard dissolution. Inhibitory effects may also result from binuclear or multinuclear binding of ligands (Figure 5). Obviously, the formation of surface films (heterogeneous nucleation, surface precipitation) and subsequent phase transformations at the surface as it may, for example, occur with phosphates, or silicate on Fe(III)(hydr)oxide surfaces, modifies surface reactivity. These effects are also of significance in metal corrosion (passivity of oxide films).

Adsorbed species (ligands or metal ions) acquire, if they are inner-spherically bound, a different reactivity than those in solution or those outer-spherically adsorbed. Surface $\mathrm{OH}$ groups act as $\sigma$ donor ligands which increase the electron density at the center of the surface-bound metal. Higher oxidation states will generally form more stable surface complexes; that is, the specific adsorption of $\mathrm{Cu}(\mathrm{II})$ should lower its redox potential with regard to $\mathrm{Cu}(\mathrm{I})(\mathrm{aq})$ [Wehrli et al., 1989]. Surface ligands can catalyze redox reactions. It has been shown, for example

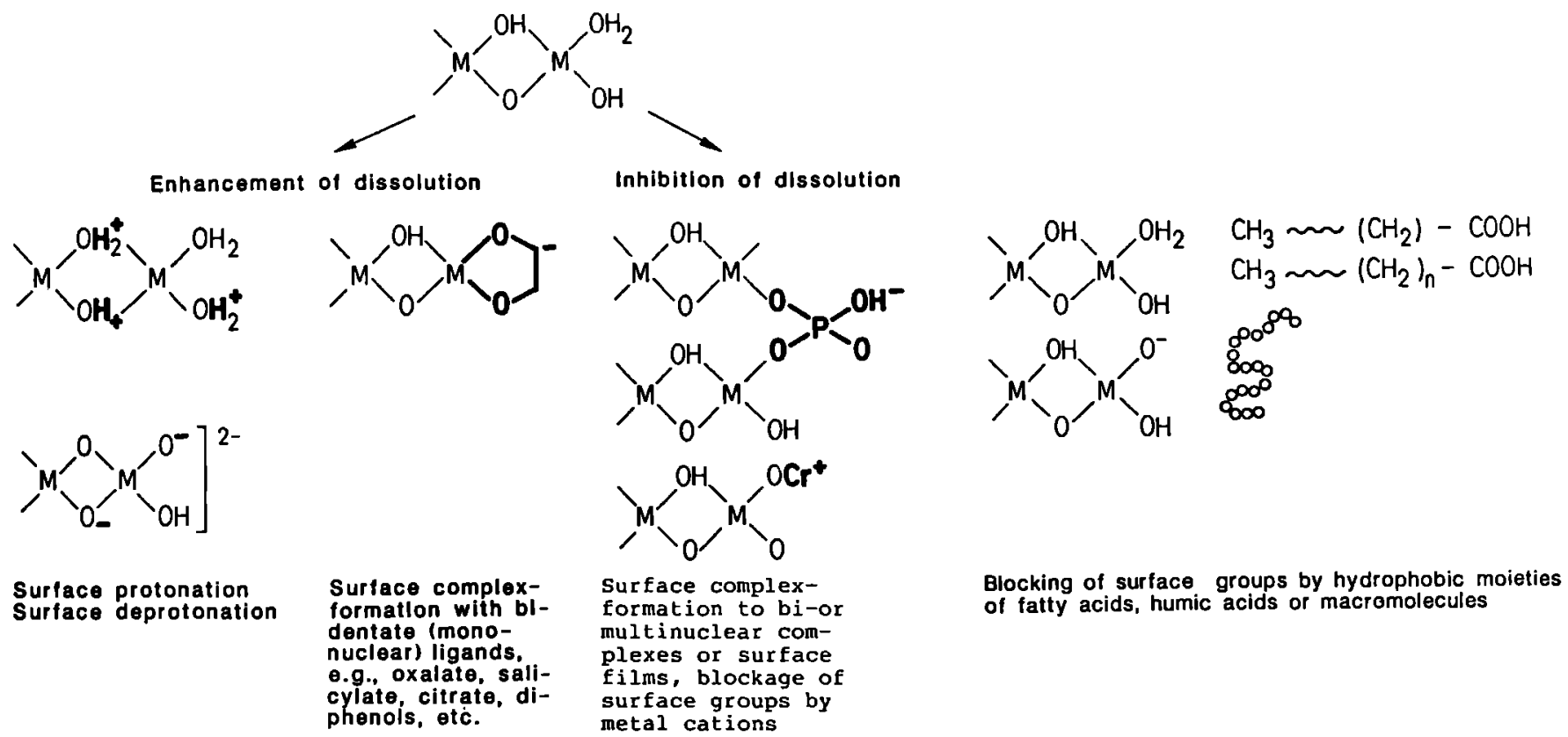

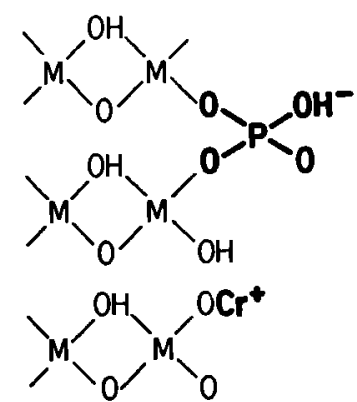

Figure 5. The dependence of surface reactivity and of kinetic mechanisms on the coordinative environment of the surface groups. 
[Wehrli and Stumm, 1988], that surface complex formation with surface hydroxyl groups catalyzes and enhances the kinetics of oxidation by oxygen of $\mathrm{VO}^{2+}, \mathrm{Fe}(\mathrm{II})$, and $\mathrm{Mn}$ (II) to a similar extent as complex formation with $\mathrm{OH}^{-}$ in solution.

The surface center, $\mathrm{M}$, of an oxide has been represented by the simplified "short-hand" notation S-OH (or $>\mathrm{M}-\mathrm{OH}$ ). This simplification permits the formulation of thermodynamic equilibria (mean field approach), but the coordination of the metal site $=\mathrm{S}$ is not specified. A surface metal center, $M$, of a simple oxide may be characterized as [Wehrli, 1989]

$$
(>\mathrm{MO})_{\sigma 1} \underset{\text { surface llgands }}{(>\mathrm{MOH})_{\sigma 2}}\left(>\mathrm{MOH}_{2}\right)_{\sigma 3} \underset{\text { terminal ligands }}{\mathrm{M}}(\mathrm{OH})_{v 1}\left(\mathrm{H}_{2} \mathrm{O}\right)_{v 2}
$$

Charges have been omitted. Here (>MOH) denotes a bridging surface $\mathrm{OH}$ group which binds the center $\mathrm{M}$ to the solid, whereas $(\mathrm{OH})$ stands for a terminal hydroxyl group. Terminal groups are coordinated only to one metal center and point toward the liquid. The stoichiometric coefficients $\sigma_{i}$ and $v_{i}$ account for the two different ligand types. The geometry of a square lattice model reflecting in a simplified way an octahedral coordination is shown in Figure 6. There are adatoms, ledges, kinks, steps, and defect sites. The dissolution is favored at a few localized (active) sites, where the reaction has lower activation energy. The overall dissolution rate is the sum of the rates of the various types of sites. The reactions occurring at differently active sites are parallel reaction steps occurring at different rates. In parallel reactions the fast reaction is rate determining. If the ratio of active sites to total sites remains constant during the dissolution (i.e., the active sites are continuously regenerated), steady state conditions are maintained, and a "mean field" rate law can generalize the dissolution rate.

Figure 6. The geometry of a square lattice surface model. The five different surface sites are (1) adatom, (2) ledge, (3) kink, (4) step, and (5) face. The five types of octahedral surface complexes are bonded to $1,2,3,4$, and 5 neighboring surface links (ligands). From the point of view of surface reactivity (e.g., dissolution rate), obviously the various surface sites have different activation energies, the adatom site (1) is most reactive, and the face site (5) (linked to five neighboring sites) is least reactive. The overall dissolution rate is based on the parallel dissolution reactions of all sites, but the overall dissolution kinetics is dictated by the fastest individual reaction rate. The latter is essentially given by the product of the first-order reaction rate specific for each type of site and the relative concentration of surface sites of each category. Monte Carlo methods, where individual activation energies were assigned to the distinct sites, were able to show that a steady state distribution of the various surface sites can be maintained during the dissolution and that one type of surface site essentially accounts for the overall dissolution rate. The model [Wehrli, 1989] suggests that the kink sites (3), although reacting much slower than ledge and adatom sites but being present at much higher relative concentrations than the less linked surface sites, control the overall dissolution rate.
The fact that constant linear dissolution rates are experimentally obtained over long time periods is in line with this steady state assumption. Further evidence comes from Monte Carlo simulations of the dissolution kinetics (Figure 6). Wehrli [1989] has studied the interdependence of surface morphology and the dissolution kinetics of minerals by means of such simulations. This lattice statistical approach was able to model zero-order dissolution kinetics and to show the evolution of steady state surface morphologies with constant mole fractions of the different reaction sites. On the molecular scale, the constant roughness of dissolving mineral grains may be regulated by the kinetic process itself.

\section{DISSOLUTION MECHANISMS}

\section{Dissolution Scenarios}

We will first describe a relatively simple scenario for the enhancement of the dissolution of $\mathrm{Al}_{2} \mathrm{O}_{3}$ by a complex-forming ligand. As we have seen (Figure 3), ligands tend to become adsorbed specifically and to form surface complexes with the Al(III) Lewis acid centers of the hydrous oxide surface. They also usually form complexes with the $\mathrm{Al}$ (III) in solution. Complex formation in solution increases the solubility. This has no direct effect on the dissolution rate, however, since the dissolution is surface controlled.

The enhancement of the dissolution rate by a ligand in a surface-controlled reaction implies that surface complex formation facilitates the release of ions from the surface to the adjacent solution. These ligands bring negative charge into the coordination sphere of the surface $\mathrm{Al}$ species, lowering their Lewis acidity. This may polarize the critical Al-oxygen bonds, thus facilitating the detachment of the Al from the surface. It has been shown that bidendate

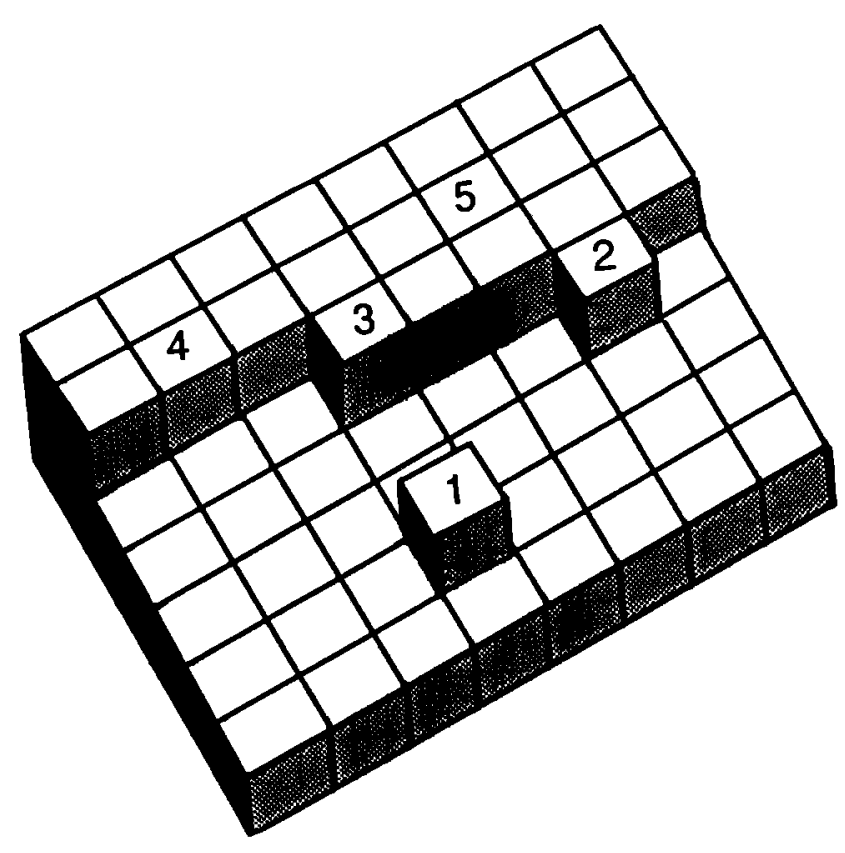


ligands (i.e., ligands with two donor atoms) such as dicarboxylates and hydroxycarboxylates, e.g., oxalate (see Figure $3 a$ ), can form relatively strong surface chelates, i.e., ring-type surface complexes.

In Figure 7 a simple scheme of reaction steps is proposed. Some of the assumptions of our model are summarized in Table 1. The short-hand representation of a surface site is a simplification that does not take into account either detailed structural aspects of the oxide surface or the oxidation state of the metal ion and its coordination number. It implies (model assumption 2 in Table 1) that all functional surface groups, such as those in a crosslinked polyhydroxo-oxo acid, are identical.

The scheme in Figure 7 indicates that the ligand, for example, oxalate, is adsorbed very fast in comparison to the dissolution reaction [Hachiya et al., 1984; Ikeda et al., 1982]; thus adsorption equilibrium may be assumed. The surface chelate formed is able to weaken the original Al-oxygen bonds on the surface of the crystal lattice. The detachment of the oxalato-aluminum species is the slow and rate-determining. step. The negative charge of the surface site after detachment is neutralized by two subsequent fast protonation steps. When initial sites are regenerated completely after the detachment step and provided that the concentrations of the reactants are kept constant, steady state conditions with regard to the oxide surface species are established (Table 1). If, furthermore, the system is far from dissolution equilibrium, the back reaction can be neglected, and constant dissolution rates occur.

The scheme of Figure $7 a$ corresponds to steady state conditions (Table 1). We can now apply the general rate law (equation (8)); the rate of the ligand-promoted dissolution, $R_{\mathrm{L}}$, is proportional to the concentration of surface sites occupied by $\mathrm{L}$ (metal-ligand complex, $>\mathrm{ML}$ ) or to the surface concentration of ligands, $C_{\mathrm{L}}^{s}\left(\mathrm{~mol} \mathrm{~m}^{-2}\right)$; i.e., $P_{j}$ in (10) is proportional to the surface area concentration of $\mathrm{L}$,

Figure 7. (a) The ligand-catalyzed dissolution reaction of a $\mathrm{Me}_{2} \mathrm{O}_{3}$ mineral can be described by three elementary steps: a fast ligand adsorption equilibrium, a slow detachment process, and a fast protonation after the rate-determining step. (b) In accordance with the reaction scheme of Figure $7 a$ the rate of ligandcatalyzed dissolution of $\delta-\mathrm{Al}_{2} \mathrm{O}_{3}$ by the aliphatic ligands oxalate, malonate, and succinate, $R_{\mathrm{L}}$ (nmol $\mathrm{m}^{-2} \mathrm{~h}^{-1}$ ) can be interpreted as a linear dependence on the surface concentrations of chelate complexes, $C_{\mathrm{L}}^{s}$. In each case the individual values for $C_{\mathrm{L}}^{s}$ were determined experimentally [Furrer and Stumm, 1986].

a)

1)

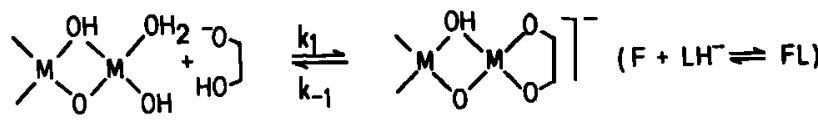

2)

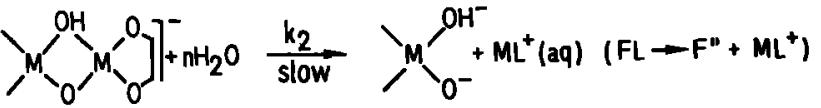

3) $\mathrm{M}_{\mathrm{O}^{-}}^{\mathrm{OH}^{-}}+2 \mathrm{H}^{+}$ $\frac{k_{3}}{\text { fast }} \nearrow_{M}^{\mathrm{OH}_{2}}$ $\left(F^{\prime \prime}+2 H^{+}-F\right)$

$$
R_{\mathrm{L}}=k_{\mathrm{L}}^{\prime}\{>\mathrm{ML}\}=k_{\mathrm{L}}^{\prime} C_{\mathrm{L}}^{s}
$$

where $k_{\mathrm{L}}^{\prime}$ is the reaction constant. $C_{\mathrm{L}}^{s}$, the surface concentration of the ligand (oxalate) $\left[\mathrm{mol} \mathrm{m}^{-2}\right]$, was determined experimentally by generalizing the quantity of oxalate that was removed from the solution by adsorption and

\section{TABLE 1. Model Assumptions}

\begin{tabular}{cl}
\hline $\begin{array}{c}\text { Text } \\
\text { Reference }\end{array}$ & \multicolumn{1}{c}{ Assumption } \\
\hline 1 & Dissolution of slightly soluble hydrous oxides \\
& o surface process is rate controlling \\
& o back reactions can be neglected if far from \\
& equilibrium
\end{tabular}

2 The hydrous oxide surface, as a first approximation, is treated as a cross-linked polyhydroxo-oxo acid o all functional groups are identical

3 Steady state of surface phase

o constancy of surface area

o regeneration of active surface sites

4 Surface defects, such as steps and kinks, establish surface sites of different activation energy, with different rates of reaction:

active sites $\stackrel{\text { faster }}{\longrightarrow} \mathrm{Me} \cdot \mathrm{aq}$
less active sites
Overall rate is given by $(a)$
o steady state condition can be maintained if a
constant mole fraction $\chi_{a}$ of active sites to total
(active and less active) sites is maintained, i.e.,
if active sites are continuously regenerated

5 Precursor of activated complex:

o metal centers bound to surface chelate, or surrounded by $j$ protonated functional groups

o $\left(C_{\mathrm{H}}^{s} / S\right)<<1$

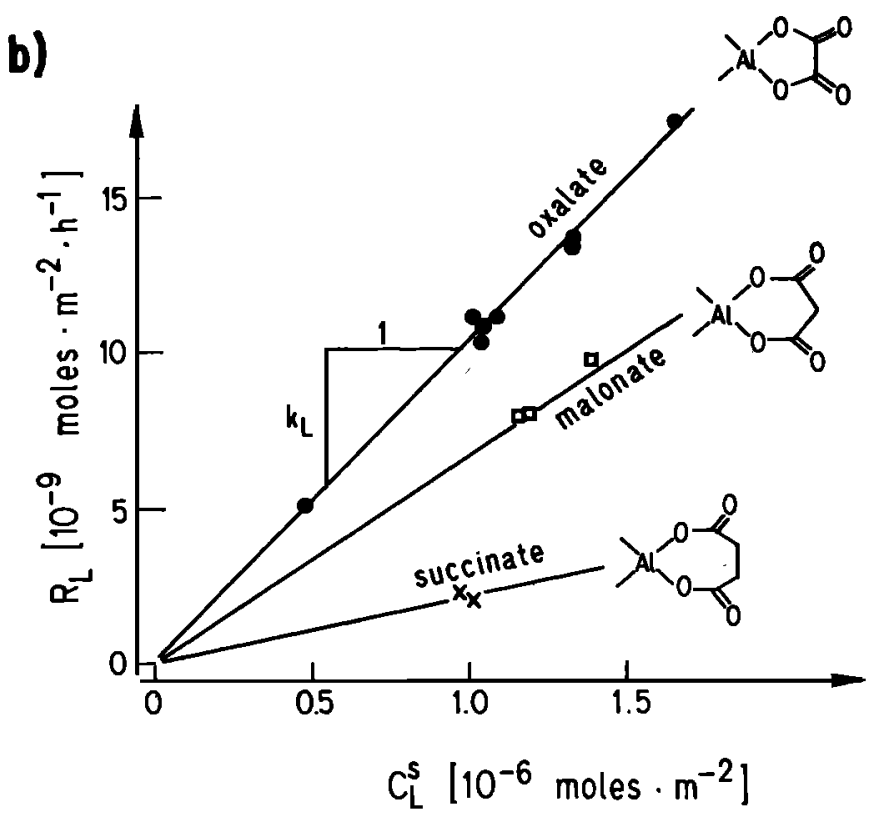


the specific surface area of the $\mathrm{Al}_{2} \mathrm{O}_{3}$. The relationship between surface concentration and solute concentration is also obtained from the ligand exchange equilibrium constant, such as equation (35) [Sigg and Stumm, 1981]. As shown in Figure $7 b$, the experimental results are in accord with equation (39).

However, we have to reflect on one of our model assumptions (Table 1). It is certainly not justified to assume a completely uniform oxide surface. The dissolution is favored at a few localized (active) sites where the reactions have lower activation energy. The overall reaction rate is the sum of the rates of the various types of sites. The reactions occurring at differently active sites are parallel reaction steps occurring at different rates (Table 1). In parallel reactions the fast reaction is rate determining [Lasaga, 1981]. We can assume that the ratio (mole fraction, $\chi_{a}$ ) of active sites to total (active plus less active) sites remains constant during the dissolution; that is, the active sites are continuously regenerated after $\mathrm{Al}$ (III) detachment, and thus steady state conditions are maintained. The reaction consant $k_{\mathrm{L}}^{\prime}$ in equation (39) includes $\chi_{a}$, which is a function of the particular material used (cf. (10)). In the activated complex theory the surface complex is the precursor of the activated complex (Figure 2) and is in local equilibrium with it. The detachment corresponds to the desorption of the activated surface complex.

\section{The Proton-Promoted Dissolution Reaction}

The dissolution reaction under acid conditions requires protons, which get bound to the surface oxide ions and weaken the critical bonds; thus detachment of the metal species into the solution results. Another part of the consumed protons replaces the metal ions, leaving the solid surface and thus maintaining the charge balance.

A scheme for the dissolution reaction of a trivalent oxide is given in Figure 8. Although this representation cannot account for individual crystallographic structures, it attempts to illustrate a typical sequence of the reaction steps which occur on the surface. The adsorption of protons at the surface is very fast [Hachiya et al., 1984]; thus surface protonation is faster than the detachment of the metal species, so it can be assumed that the concentration of protons at the surface is in equilibrium with the solution. Surface protonation may be assumed to occur at random. But the protons may move fast from one functional group to another and occupy terminal hydroxyl as well as bridging oxo or hydroxo groups. Tautomeric equilibria may be assumed. The detachment process (step 4 in Figure 8) is (far from equilibrium) the slowest of the consecutive steps. If the steady state conditions are maintained, the following equation describes the overall reaction rate:

$$
R_{\mathrm{H}}=k_{4}\{D\}
$$

Under steady state conditions, i.e., if the original surface sites are regenerated completely after the detachment step (Table 1) and if it is assumed that surface protonation equilibria are retained and kept constant by controlling the solution $p \mathrm{H}$, one may write

$$
d[\mathrm{~A}] / d t=d[\mathrm{~B}] / d t=d[\mathrm{C}] / d t=d[\mathrm{D}] / d t=0
$$

If the fraction of surface that is covered with protons is smaller than $1\left(\chi_{H} \ll 1\right)$, the surface density of singly, doubly, and triply protonated surface sites $(B, C$, and $D$, respectively (see Figure 8)) can be described as probability functions of the surface protonation $C_{\mathrm{H}}^{s}$.

A weakening of the critical metal-oxygen bonds occurs as a consequence of the protonation of the oxide ions neighboring a surface metal center. The concentration (activity) of D should reflect that three of such oxide or hydroxide ions have to be protonated. If there is a certain number of surface-adsorbed (bound) protons whose concentration $C_{\mathrm{H}}^{s}\left(\mathrm{~mol} \mathrm{~m}^{-2}\right)$ is much lower than the density of surface sites, $S\left(\mathrm{~mol} \mathrm{~m}^{-2}\right)$, the probability of finding a metal center surrounded with three protonated oxide or hydroxide ions is proportional to $\left(C_{\mathrm{H}}^{s} / S\right)^{3}$. Thus, as has been derived from lattice statistics by Wieland et al. a)<smiles>[Tl]</smiles>
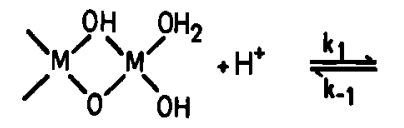<smiles></smiles>

2)
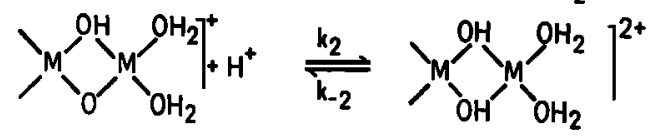

3)

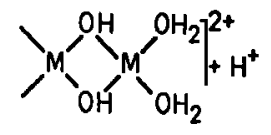

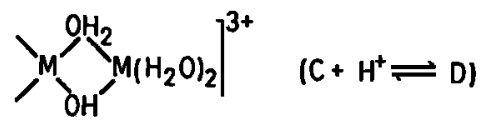

4)

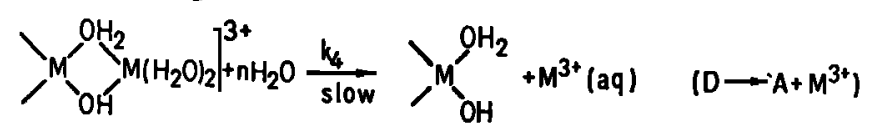

b)

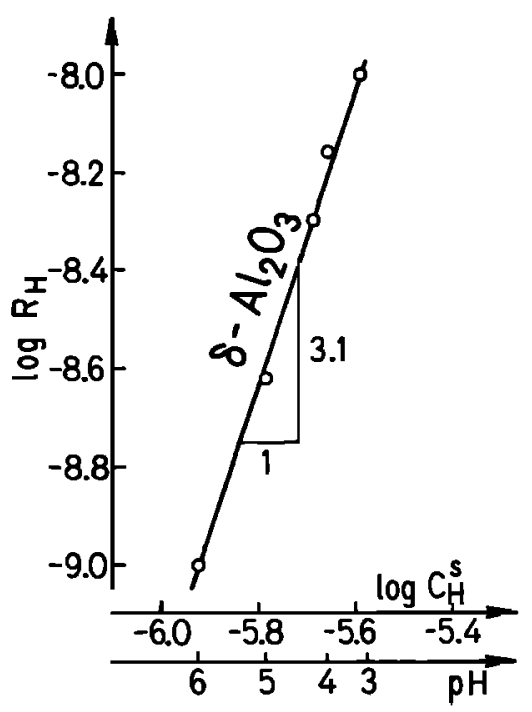

Figure 8. (a) Schematic representation of the proton-promoted dissolution process. A reaction mechanism for the dissolution of $\mathrm{M}_{2} \mathrm{O}_{3}$ with three preceding protonation steps is shown. (b) The dependence of the rate of proton-promoted dissolution of $\delta-\mathrm{Al}_{2} \mathrm{O}_{3}, R_{\mathrm{H}}\left(\mathrm{mol} \mathrm{m} \mathrm{m}^{-2} \mathrm{~h}^{-1}\right)$, on the surface concentration of protons, $C_{\mathrm{H}}^{\mathrm{H}}\left(\mathrm{mol} \mathrm{m}^{-2}\right)$ [ Furrer and Stumm, 1986].

$$
\begin{aligned}
& \left(A+H^{+} \rightleftharpoons B\right) \\
& \left(B+H^{+} \rightleftharpoons C\right) \\
& \left(C+H^{+} \rightleftharpoons D\right)
\end{aligned}
$$




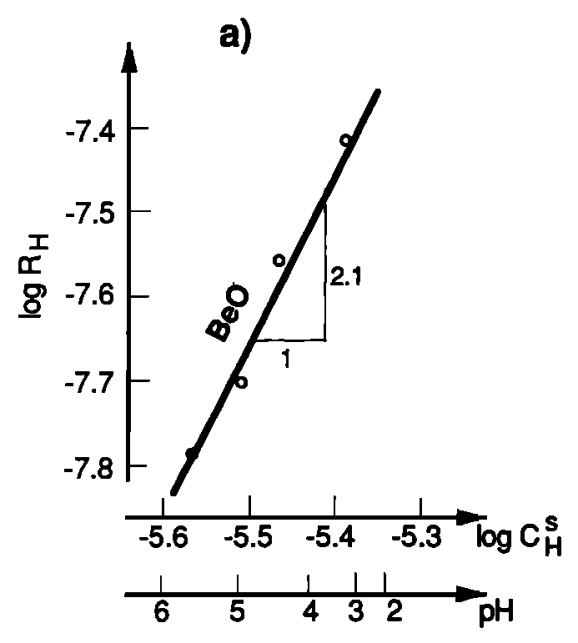

Figure 9. The dependence of the rate of dissolution, $R_{\mathrm{H}}$ or $R_{\overline{\mathrm{O}}}$ $\left(\mathrm{mol} \mathrm{m} \mathrm{m}^{-2} \mathrm{~h}^{-1}\right.$ ), of BeO [Furrer and Stumm, 1986], $\alpha-\mathrm{FeOOH}$ [Zinder et al., 1986], and $\mathrm{SiO}_{2}$ (quartz) [Guy and Schott, 1989;

[1988], the activity of $\mathrm{D}$ is related to $\left(C_{\mathrm{H}}^{s}\right)^{3}$, and the rate of proton-promoted dissolution, $R_{\mathrm{H}}\left(\mathrm{mol} \mathrm{m}^{-2} \mathrm{~h}^{-1}\right)$, is proportional to the third power of the surface protonation:

$$
R_{\mathrm{H}} \propto[\mathrm{D}] \propto\left(C_{\mathrm{H}}^{s}\right)^{3}
$$

that is,

$$
R_{\mathrm{H}}=k_{\mathrm{H}}^{\prime}\left\{>\mathrm{MeOH}_{2}^{+}\right\}^{3}
$$

For another oxide, for which the dissolution mechanism requires only two preceding protonation steps, the rate would be proportional to $\left(C_{\mathrm{H}}^{s}\right)^{2}$. Generally, for all oxides, which dissolve by an acid-promoted surface-controlled process, the following rate equation may be postulated (Figure 9):

$$
R_{\mathrm{H}} \propto\left\{\mathrm{MeOH}_{2}^{+}\right\}^{j}
$$

where $j$ is an integer if dissolution occurs by one mechanism only. If more than one mechanism occur simultaneously, the exponent $j$ will not be an integer.

\section{Enhancement of Dissolution by Deprotonation}

The dissolution rate of most oxides increases both with increasing surface protonation and with decreasing surface deprotonation, equivalent to the binding of $\mathrm{OH}^{-}$ligands; thus in the alkaline range the dissolution rate increases with increasing $p \mathrm{H}$ [Chou and Wollast, 1984; Schott, 1990; Brady and Walther, 1990].

\section{The Overall Rate of Dissolution}

The surface charge of the mineral is an important factor in the polarization of the lattice bonds on the surface. Thus one may generalize that the dissolution rate is related to the surface charge imparted to the surface by $\mathrm{H}^{+}$and/or $\mathrm{OH}^{-}$; the rate increases both with increasing positive surface charge with decreasing $p \mathrm{H}$ values of the solution and with increasing negative surface charge with increasing $p \mathrm{H}$ values. The minimum dissolution rates are observed at the $p \mathrm{H}_{\mathrm{ZPC}}$.

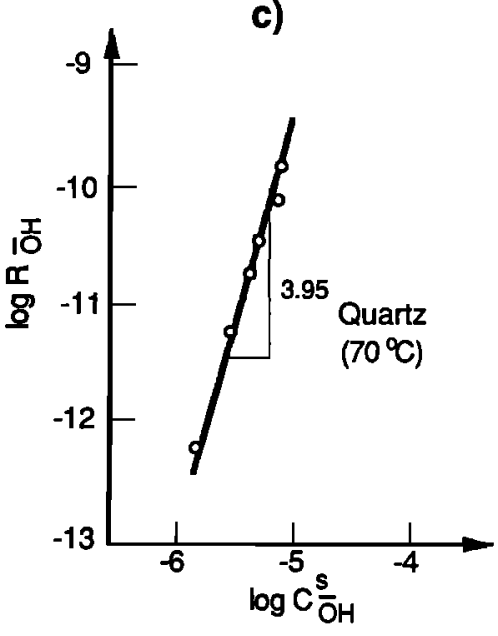

Knauss and Wolery, 1989] on the surface concentration of protons, $C_{\mathrm{H}}^{s}$, or hydroxide ions, $C_{\overline{\mathrm{OH}}}^{\mathrm{s}}\left(\mathrm{mol} \mathrm{m}^{-2}\right)$.

The overall rate of dissolution is given by

$$
R=k_{\mathrm{H}}^{\prime}\left(C_{\mathrm{H}}^{s}\right)^{j}+k_{\mathrm{OH}}^{\prime}\left(C_{\overline{\mathrm{OH}}}^{s}\right)^{i}+k_{\mathrm{L}}^{\prime}\left(C_{\mathrm{L}}^{s}\right)+k_{\mathrm{H}_{2} \mathrm{O}}^{\prime}
$$

the sum of the individual reaction rates, assuming that the dissolution occurs in parallel at different metal centers [Furrer and Stumm, 1986].

Because the binding of protons and of $\mathrm{OH}^{-}$ions on other anions (ligands) to the surface $\mathrm{OH}$ groups imposes positive or negative, respectively, surface charge on the oxide, it is evident (see equation (43)) that the dissolution rate is related to the charge (positive or negative).

\section{Lattice Statistics}

Most generally, a solute that becomes bound to a surface site may make this surface site (the central metal unit) more or less detachable. The increasing rate of dissolution of most minerals with increasing $\left[\mathrm{H}^{+}\right]$in solution is caused by the protonation of the surface (in excess relative to the point of zero proton charge). But $P_{j}$, the probability of precursor arrangement, is not simply equal to the molar fraction $\chi_{\mathrm{H}}=C_{\mathrm{H}}^{s} / S$; the geometric coordinative arrangement of the bound surplus protons corresponding to the net positive surface charge is of particular importance. The protons may be assumed to be relatively mobile in the surface layer; that is, they can be shifted, for example, from $\mathrm{OH}$ groups to neighboring oxygen bridges. Recent experimental evidence indicates that protons at interfaces are extremely mobile [Prats et al., 1986], which could result in fast random motion among surface sites. In a simplifying way, a random distribution of surplus protons in the surface layer may be assumed. A sufficient weakening of the critical metal-oxygen bond occurs if a sufficient number $j$ of oxide or hydroxide groups neighboring the surface central metal ion (in the case of the surface of $\delta-\mathrm{Al}_{2} \mathrm{O}_{3}, j=3$; in the case of $\mathrm{BeO}, j=2$ [Furrer and Stumm, 1986]; and in the case of $\mathrm{SiO}_{2}, j=4$ [Schott, 
1990]) have become protonated. Thus we need a quantitative relationship between $P_{j}$ and the mole fraction of surface-bound $\mathrm{H}^{+}, \chi_{\mathrm{H}}$. The question is, How does the probability of a metal center to be surrounded by $j(0,1,2$, 3 , or 4) protonated functional groups depend on surface protonation and, in turn, on $\left[\mathrm{H}^{+}\right]$in solution?

To derive the appropriate equations we need only to define the geometry of the lattice and to exploit the basic assumption: random distribution of species. The chessboard geometry is a convenient way to represent two surface species (metal centers $\mathrm{M}_{j}$ and $\mathrm{OH}$ groups with $\mathrm{a} 1$ : 1 stoichiometry). If the hydroxyl species are allowed to be randomly protonated, we may distinguish five types of metal sites $M_{j}$, according to the number of nearestneighbor protons $(j=0,1,2,3,4)$. In the absence of other species the probability of finding a hydroxyl group in the protonated or uncharged state is equal to $\chi_{\mathrm{H}}$ or $\left(1-\chi_{\mathrm{H}}\right)$, respectively. The probability $P_{j}$ of finding a metal site surrounded by both $j$ protonated and $(4-j)$ uncharged $\mathrm{OH}$ groups is given by the Bernoulli scheme [de Finetti, 1974; Wieland et al., 1988]:

$$
P_{j}=\frac{4 !}{j !(4-j) !} \cdot \chi_{\mathrm{H}}^{j} \cdot\left(1-\chi_{\mathrm{H}}\right)^{4-j}
$$

The first factor on the right-hand side represents the number of possible geometric arrangements of $j$ protons on four neighbor sites.

The maximum proton density that results from titration experiments is typically 10 times smaller than the crystallographic site density $S$. As a consequence the mole fraction $\chi_{H}$ becomes $<<1$, and equation (44) simplifies for real systems to

$$
P_{j} \cong \chi_{\mathrm{H}}^{j} \quad p_{j} \propto\left(C_{\mathrm{H}}^{s}\right)^{j}
$$

In other words, the probability of finding three surplus protons in the immediate neighborhood of a surface trivalent metal center, such as $\mathrm{Al}$ in $\mathrm{Al}_{2} \mathrm{O}_{3}$, is essentially proportional to the third power of the (surplus) proton surface density. For a more detailed derivation, see Wieland et al. [1988].

\section{Experimentally Accessible Parameters}

Surface protonation and deprotonation are experimentally directly accessible from alkalimetric or acidimetric surface titrations. The surface concentrations $\left[>\mathrm{MOH}_{2}^{+}\right.$] or $\left\{>\mathrm{MO}^{-}\right\}$are nonlinearily related to $\mathrm{H}^{+}$by surface complex formation equilibria (29) and (32) or by semiempirical relations such as (34); in other words,

$$
\left\{>\mathrm{MOH}_{2}^{+}\right] \propto\left[\mathrm{H}^{+}\right]^{n} \quad\left[>\mathrm{MO}^{-}\right] \propto\left[\mathrm{H}^{+}\right]^{-m}
$$

Many authors have shown the empirical rate law

$$
R_{\mathrm{H}}=k_{\mathrm{H}}\left[\mathrm{H}^{+}\right]^{n}
$$

where $n$ is typically between 0 and 0.5 . These observations are relevant for the assessment of the impact of acid rain on weathering rates. As equation (47) suggests, the rate of weathering does not increase linearly with the acidity of the water. A tenfold increase in $\left[\mathrm{H}^{+}\right]$leads to an increase in the dissolution rate by a factor of about 2-3. Similarly, in the alkaline range the empirical rate law holds:

$$
R_{\mathrm{OH}}=k_{\mathrm{OH}}\left[\mathrm{H}^{+}\right]^{-m}
$$

\section{Activation Energy of the Rate-Determining Step}

The activated complex theory provides a model to bridge the gap between thermodynamic information (surface coordination and lattice or site energy) and kinetic information. The rate constant $k$ is related to the free energy of conversion $\left(\Delta \mathrm{G}^{0 \ddagger}\right.$ or $\Delta \mathrm{H}^{0 \ddagger}$ ) of a suitable surface complex (precursor to an activated surface complex) (Figure 2); this energy can be compared according to the Arrhenius theory with the activation energy $E_{a}$ of the ratedetermining step. The fact that for many minerals a consistent relationship was found between the apparent activation energy $E_{\text {app }}$ (from the temperature dependence of the overall dissolution rate) and the dissolution rate [Wieland et al., 1988] lends support to the inference that $E_{\text {app }}$ is often a good approximation of $E_{a}$. Thus one may postulate that the rate constant $k_{\mathrm{H}}$ is mainly a measure of the metal-oxygen bond broken in the rate-determining step of a detachment reaction.

\section{Application of a General Dissolution Rate to Crystalline Mixed Oxides}

Interpretation of the dissolution reaction is rendered more involved in the case of crystalline mixed oxides (like olivine and feldspars) because, understandably, it is more difficult to characterize the surface chemistry of crystalline mixed oxides. Furthermore, in many instances the dissolution of a silicate mineral is incipiently incongruent. As has been mentioned, this initial incongruent dissolution step is usually followed by a congruent dissolution-controlled surface reaction. Wollast and Chou [1985] and Blum and Lasaga [1988] determined the influence of $p \mathrm{H}$ on the dissolution rate of albite and olivine, respectively. Dissolution rates depend on surface speciation. This dependence is typical and illustrates the enhancement of the dissolution rate by surface protonation and surface deprotonation. Near the $p \mathrm{H}_{\mathrm{ZPC}}$, often a zero-order dependence on $\left[\mathrm{H}^{+}\right]$has been reported; this is generally interpreted in terms of a hydration reaction of the surface (see equation (43)).

As the study of the dissolution of kaolinite and muscovite [Wieland, 1988; Caroll-Webb and Walther, 1988; Stumm and Wieland, 1990] illustrates, the dissolution behavior of complex oxides can be modeled from the properties of their constituent oxide components.

The application of these concepts to the weathering of a wide variety of crystalline mixed oxides (like olivine and feldspars) and the experimental approaches used in these studies are discussed in a review by $R$. Wollast and $W$. Stumm (work in preparation, 1990). It is shown by 
Figure 10. The dissolution of Fe(III) (hydr)oxides promoted by reductive organic ligands plays an important role in soils and sediment water systems and causes relatively rapid cycling of electrons and of reactive elements (e.g., organic carbon, oxygen, trace metals, phosphate) at the oxic-anoxic boundary. This cycle can also occur, photochemically induced, in oxic surface waters.

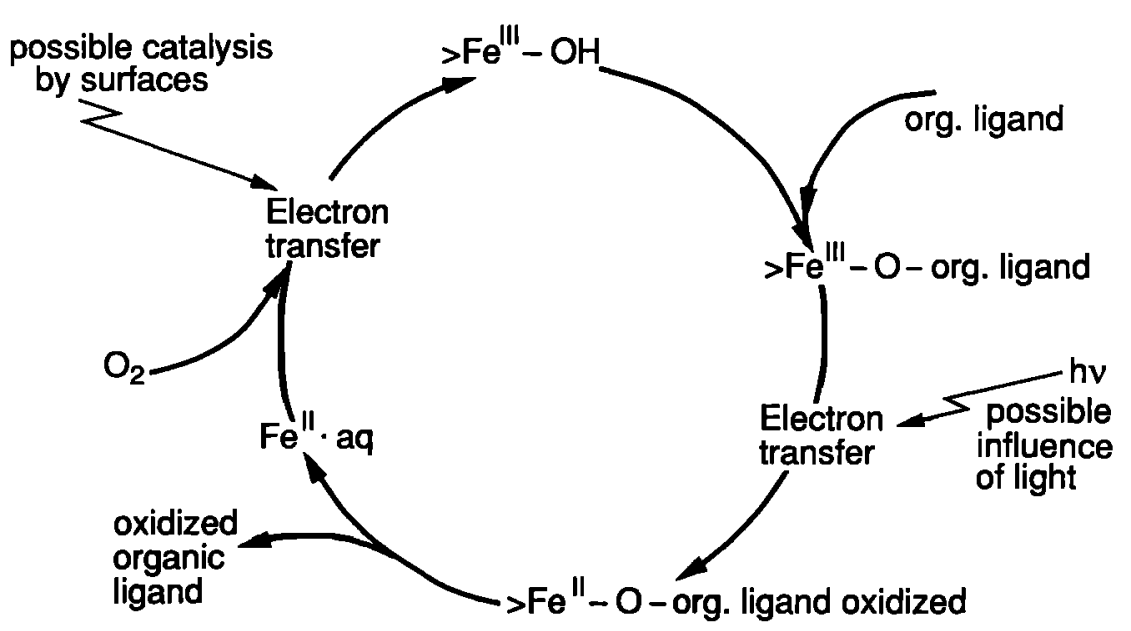

Sulzberger et al. [1989] and by Sulzberger [1990] that the kinetics of reductive dissolution of iron(III) oxides are also characterized by surface-chemical reactions.

\section{Reductive Dissolution of Oxide Minerals, an Important Transformation in Geochemical Cycling of Electrons}

Changes in oxidation state affect the solubility of metal (hydr)oxides [Stone and Morgan, 1987]. The oxides of transition elements become more soluble upon reduction; other oxides such as $\mathrm{Cr}_{2} \mathrm{O}_{3}$ or $\mathrm{V}_{2} \mathrm{O}_{3}$ become more soluble upon oxidation. The reduction of surface metal centers in reducible metal oxides typically leads to easier detachment of the reduced metal ions from the lattice surface. This is readily accounted for by the larger lability of the reduced metal-oxygen bond in comparison to the nonreduced metal-oxygen bond; for example, the site energy of the $\mathrm{Fe}^{\mathrm{II}}-\mathrm{O}$ bond in a crystalline lattice is much smaller than that of the $\mathrm{Fe}^{\mathrm{III}}-\mathrm{O}$ bond. As shown by Sulzberger et al. [1989], the dissolution rate in each case investigated was controlled by surface chemical reactions; specifically, in the dissolution of $\mathrm{Fe}(\mathrm{III})$ (hdyr)oxides by reductants the rate was found to be proportional to the concentration of the surface-bound reductant:

$$
R_{\text {Reductive }} \propto[>\mathrm{Fe}-\mathrm{O}-\text { Reductant }]
$$

The cycling of manganese [Stone and Morgan, 1987] and of iron [Sulzberger et al., 1989] is of great importance to the geochemical cycling of electrons. Figure 10 illustrates the role played by weathering of iron (III) oxides in the transformation of organic matter (oxidation and oxidative polymerization).

The continuous cycle of reduction dissolution accompanied by the release of reactive elements, and subsequent oxidation precipitation accompanied by bonding of reactive compounds, is of great importance for metabolic transformations in soils and in marine and lacustrine sediment water systems and the coupling of the iron cycle with that of other elements (oxygen, trace metals, phosphate, silicate). These processes occur at the oxic-anoxic bound- aries; because they are affected by light (photochemical excitation of the iron(III) surface complex or of iron(III) (hydr)oxide as a semiconductor), they can also occur in oxic environments in surface waters and in atmospheric waters.

\section{CONCLUDING REMARKS}

The fundamental chemical interaction of solutes with natural surfaces occurs through the formation of coordinative bonds. These specific chemical factors need to be considered in order to derive rate laws for geochemical processes such as the dissolution and weathering of rocks and the formation of minerals. Surface processes rather than transport processes are the rate-controlling steps in the dissolution of most oxides and aluminum silicates. The tendency of a mineral to dissolve is influenced by the interaction of solutes $\left(\mathrm{H}^{+}\right.$and $\mathrm{OH}^{-}$, ligands (anions and weak acids), and metal ions) with its surface. The surface reactivity is dependent on the surface species and their structural identity. Specifically, the dependence of dissolution rate on $p \mathrm{H}$ and on dissolved ligand concentrations can be explained in terms of the surface concentration (activities) of the precursor of the activated complex; these surface concentrations are experimentally determinable from the number of surface sites, the extent of surface protonation (or deprotonation), and the surface concentration of ligands. Furthermore, the weathering rate of different minerals depends on the structural arrangements within the crystal lattice and on the strength of the bonds between the atoms of the crystal that have to be broken. Weathering processes participate in controlling the hydrogeochemical cycles of many elements.

ACKNOWLEDGMENTS. The work of $\mathrm{W}$. Stumm on the coordination chemistry of the solid-water interface has been supported for the last 10 years by the Swiss National Foundation. Crucial phases of our research have profited from collaboration with Lei Chou, Gerhard Furrer, Laura Sigg, Barbara Sulzberger, Bernhard Wehrli, and Erich Wieland. We thank M. Neugebauer, the editor in chief, and Garrison Sposito for their great efforts in 
improving this paper. We are also indebted to the reviewers, $\mathbf{G}$. R. Holdren and S. Carroll, for valuable constructive suggestions.

Garrison Sposito was the editor in charge of this paper. He thanks George Holdren and Susan A. Carroll for serving as technical referees.

\section{REFERENCES}

Anderson, M. A., J. F. Ferguson, and J. Gavis, Arsenate adsorption on amorphous aluminum hydroxide, $J$. Colloid Interface Sci., 54, 391, 1976.

Berner, R. A., and A. C. Lasaga, Modelling the geochemical carbon cycle, Sci. Am., 260(3), 54-61, 1989.

Bemer, R. A., and J. Schott, Mechanism of feldspar weathering, II, Observations of feldspars from soils, Geochim. Cosmochim. Acta, 43, 1173-1186, 1982.

Bemer, R. A., A. C. Lasaga, and R. M. Garrels, The carbonatesilicate geochemical cycle and its effect on atmospheric carbon dioxide over the past two million years, Am. J. Sci., 283, 641-683, 1983.

Blum, A. E., and A. C. Lasaga, Role of surface speciation in the dissolution of minerals, Nature, 331, 341-343, 1988.

Brady, P. V., and J. V. Walther, Controls on silicate dissolution rates in neutral and basic $p \mathrm{H}$ solutions at $25^{\circ} \mathrm{C}$, Chem. Geol., in press, 1990.

Brown, G. E., Jr., G. A. Parks, and C. J. Chisholm-Brause, Insitu X-ray absorption spectroscopic studies of ions at oxidewater interfaces, Chimia, 43, 248-256, 1989.

Burgess, J., Metal Ions in Solution, Ellis Horwood, Chichester, England, 1978.

Busenberg, E., and C. V. Clemency, The dissolution kinetics of feldspars at $25^{\circ} \mathrm{C}$ and $1 \mathrm{~atm} \mathrm{CO}_{2}$ partial pressure, Geochim. Cosmochim. Acta, 40, 41-49, 1976.

Caroll-Webb, S. A., and J. V. Walther, A surface complex formation model for the $p \mathrm{H}$-dependence of corundum and kaolinite dissolution rates, Geochim. Cosmochim. Acta, 52, 2609-2623, 1988.

Casey, W. H., H. R. Westrich, G. W. Amold, and J. F. Banfield, The surface chemistry of dissolving labradorite feldspar, Geochim. Cosmochim. Acta, 53, 821-832, 1989.

Chisholm-Brause, C. J., G. E. Brown, Jr., and G. A. Parks, EXAFS investigation of aqueous $\mathrm{Co}$ (II) adsorbed on oxide surfaces in-situ, Geochim. Cosmochim. Acta, in press, 1989.

Chou, L., and R. Wollast, Study of the weathering of albite at room temperature and pressure with a fluidized bed reactor, Geochim. Cosmochim. Acta, 48, 2205-2217, 1984.

Correns, C. W., and W. von Engelhardt, Neue Untersuchungen über die Verwitterung des Kalifeldspates, Chem. Erde, 12, 1-22, 1938.

de Finetti, B., Theory of Probability, vol. 1, 148 pp., Wiley Interscience, New York, 1974.

Eggleton, R. A., C. Foudoulis, and D. Varkevisser, Weathering of basalt: Changes in rock chemistry and mineralogy, Clays Clay Miner., 35, 161-169, 1987.

Fokking, L. G. J., Ion adsorption on oxides, Ph.D. thesis, Univ. of Wageningen, Netherlands, 1987.

Fowler, R., and E. A. Guggenheim, Statistical Thermodynamics, 693 pp., Macmillan, New York, 1939.

Frumkin, A. N., Die Kapillarkurve der höheren Fettsäuren und die Zustandsgleichung der Oberflächenschicht, Z. Phys. Chem., 116, 466-484, 1925.

Furrer, G., and W. Stumm, The coordination chemistry of weathering, I, Dissolution kinetics of $\delta-\mathrm{Al}_{2} \mathrm{O}_{3}$ and $\mathrm{BeO}$, Geochim. Cosmochim. Acta, 50, 1847-1860, 1986.

Garrels, R. M., and F. T. Mackenzie, Evolution of Sedimentary Rocks, Norton, New York, 1971.
Guy, C., and J. Schott, Multisite surface reaction versus transport control during the hydrolysis of a complex oxide, Chem. Geol., in press, 1989.

Hachiya, K., Sasaki, M., Y. Saruta, N. Mikami, and T. Yasunaga, Static and kinetic studies of adsorption-desorption of metal ions on $\gamma-\mathrm{Al}_{2} \mathrm{O}_{3}$ surface, J. Phys. Chem., 88, 23-31, 1984.

Harding, I. H., and T. W. Healy, Electrical double layer properties of amphoteric polymer latex colloids, J. Colloid Interface Sci., 107, 382-397, 1985.

Hayes, K. F., A. L. Roe, G. E. Brown, Jr., K. O. Hodgson, J. O. Leckie, and G. A. Parks, In situ X-ray absorption study of surface complexes: Selenium oxyanions on $\alpha-\mathrm{FeOOH}$, Science, 238, 783-786, 1987.

Helgeson, $H$. C., Kinetics of mass transfer among silicates and aqueous solution, Geochim. Cosmochim. Acta, 35, 421-469, 1971.

Holdren, G. R., Jr., and R. A. Berner, Mechanism of feldspar weathering, I, Experimental studies, Geochim. Cosmochim. Acta, 43, 1161-1171, 1979.

Holdren, G. R., Jr., and P. M. Speyer, pH dependent changes in the rates and stoichiometry of dissolution of a feldspar at room temperature, Am. J. Sci., 285, 994-1026, 1985.

Holland, H. D., The Chemistry of the Atmosphere and Oceans, Wiley Interscience, New York, 1978.

Ikeda, T., M. Sasaki, K. Hachiya, R. D. Astumian, R. Yasunaga, and Z. A. Schelly, Adsorption-desorption kinetics of acetic acid on silica-alumina particles in aqueous suspensions, using the pressure-jump relaxation method, J. Phys. Chem., 86, 3861-3866, 1982.

Knauss, K. G., and T. J. Wolery, Muscovite dissolution kinetics as a function of $p \mathrm{H}$ and time at $70^{\circ} \mathrm{C}$, Geochim. Cosmochim. Acta, 53, 1493-1501, 1989.

Lasaga, A. C., Transition state theory, Rev. Mineral., 8, 135-169, 1981.

Luce, R. W., R. W. Bartlett, and G. A. Parks, Dissolution kinetics of magnesium silicates, Geochim. Cosmochim. Acta, 36, 35-50, 1972.

Lyklema, J., Electrical double layers on oxides: Disparate observations and unifying principles, Chem. Ind., London, 741-747, 1987.

Meybeck, M., Concentration des eaux fluviales en éléments majeurs et apports en solution aux océans, Rev. Geol. Dyn. Geogr. Phys., 21, 215-246, 1979.

Motschi, H. Aspects of the molecular structure in surface complexes; spectroscopic investigations, in Aquatic Surface Chemistry, edited by W. Stumm, pp. 111-126, Wiley Interscience, New York, 1987.

Paces, T., Steady-state kinetics and equilibrium between ground waters and granitic rock, Geochim. Cosmochim. Acta, 37, 2641-2663, 1973.

Petit, J.-C., G. Della Mea, J.-C. Dran, J. Schott, and R. A. Berner, Mechanism of diopside dissolution from hydrogen depth profiling, Nature, 325, 705-706, 1987.

Petrovic, R., R. A. Berner, and M. B. Goldhaber, Rate control in dissolution of alkali feldspars, I, Study of residual feldspar grains by X-ray photoelectron spectroscopy, Geochim. Cosmochim. Acta, 40, 537-548, 1976.

Prats, M., J. Teissie, and J. F. Tocanne, Lateral proton conduction at lipid-water interfaces and its implications for the chemiosmotic coupling hypothesis, Nature, 322, 756-758, 1986.

Schindler, P. W., and W. Stumm, The surface chemistry of oxides, hydroxides and oxide minerals, in Aquatic Surface Chemistry, edited by W. Stumm, pp. 311-338, Wiley Interscience, New York, 1987.

Schnoor, J. L., Kinetics of chemical weathering in whole soils and watersheds, in Aquatic Chemical Kinetics, edited by W. Stumm, in press, 1990. 
Schnoor, J. L., and W. Stumm, Acidification of aquatic and terrestrial systems, in Chemical Processes in Lakes, edited by W. Stumm, pp. 311-338, Wiley Interscience, New York, 1985.

Schott, J., Modelling of the dissolution of strained and unstrained multiple oxides: The surface speciation approach, in Aquatic Chemical Kinetics, edited by W. Stumm, Wiley Interscience, New York, in press, 1990.

Schott, J., and R. A. Berner, Dissolution mechanism of pyroxenes and olivines during weathering, in The Chemistry of Weathering, NATO Adv. Study Inst. Ser., Ser. C, vol. 149, edited by J. I. Drever, pp. 35-53, D. Reidel, Hingham, Mass., 1985.

Schott, J., and J.-C. Petit, New evidence for the mechanisms of dissolution of silicate minerals, in Aquatic Surface Chemistry, edited by W. Sturm, pp. 293-312, Wiley Interscience, New York, 1987.

Schott, J., R. A. Bemer, and E. L. Sjöberg, Mechanism of pyroxene and amphibole weathering, I, Experimental studies of iron-free minerals, Geochim. Cosmochim. Acta, 45, 2123-2135, 1981.

Sigg, L., and W. Stumm, The interactions of anions and weak acids with the hydrous goethite $(\alpha-\mathrm{FeOOH})$ surface, Colloids Surf., 2, 101-117, 1981.

Sposito, G., On the surface complexation model of the oxideaqueous solution interface, J. Colloid Interface Sci., 91, 329-340, 1983.

Sposito, G., The Surface Chemistry of Soils, Oxford University Press, New York, 1984.

Stone, A., and J. J. Morgan, Chemical kinetics as applied to natural waters, in Aquatic Surface Chemistry, edited by W. Stumm, pp. 221-254, Wiley Interscience, New York, 1987.

Stumm, W. and J. J. Morgan, Aquatic Chemistry, 2nd ed., 780 pp., Wiley Interscience, New York, 1981.

Stumm, W., and E. Wieland, Dissolution of oxide minerals: Rates depend on surface speciation, in Aquatic Chemical Kinetics, edited by W. Stumm, Wiley Interscience, New York, in press, 1990.

Stumm, W., C. P. Huang, and S. R. Jenkin, Specific chemical interaction affecting the stability of dispersed systems, Croat. Chem. Acta, 42, 223-245, 1970.

Stumm, W., H. Hohl, and F. Dalang, Interaction of metal ions with hydrous oxide surfaces, Croat. Chem. Acta, 48, 491-504, 1976.

Stumm, W., R. Kummert, and L. Sigg, A ligand exchange model for the adsorption of inorganic and organic ligands at hydrous oxide interfaces, Croat. Chem. Acta, 53, 291-312, 1980.

Stumm, W., B. Wehrli, and E. Wieland, Surface complexation and its impact on geochemical kinetics, Croat. Chem. Acta, $60,429-456,1987$.

Sulzberger, B., Photoredox processes at hydrous oxide surfaces, in Aquatic Chemical Kinetics, edited by W. Stumm, Wiley Interscience, New York, in press, 1990.
Sulzberger, B., D. Suter, C. Siffert, S. Banwart, and W. Stumm, Kinetics of dissolution of $\mathrm{Fe}$ (III) (hydr)oxides in natural waters: Control by surface coordination, Mar. Chem., 28, 1-19, 1989.

Valverde, N., and C. Wagner, Considerations on the kinetics and the mechanism of the dissolution of metal oxides in acidic solutions, Ber. Bunsenges. Phys. Chem., 80, 330-333, 1976.

von Zelewsky, A., and J. M. Bemtgen, Formation of ternary copper(II)-complexes at the surface of silica gel as studied by ESR spectroscopy, Inorg. Chem., 21, 1771-1777, 1982.

Wehrli, B., Monte Carlo simulations of surface morphologies during mineral dissolution, $J$. Colloid Interface Sci., 132, 230-242, 1989.

Wehrli, B., and W. Stumm, Oxygenation of vanadyl(IV): Effect of coordinated surface hydroxyl groups and $\mathrm{OH}^{-}$, Langmuir, 4, 753-758, 1988.

Wehrli, B., B. Sulzberger, and W. Stumm, Redox processes catalyzed by hydrous oxide surfaces, Chem. Geol., 78, in press, 1989.

Wieland, E., Die Verwitterung schwerlöslicher Mineralien, ein koordinationschemischer Ansatz zur Beschreibung der Auflösungskinetik, Ph.D. thesis, no. 8532, ETHZ Swiss Federal Inst. of Technol., Zürich 1988.

Wieland, E., B. Wehrli, and W. Stumm, The coordination chemistry of weathering, III, A potential generalization on dissolution rates of minerals, Geochim. Cosmochim. Acta, 52, 1969-1981, 1988.

Wollast, R., Kinetics of the alteration of K-feldspar in buffered solutions at low temperature, Geochim. Cosmochim. Acta, 31, 635-648, 1967.

Wollast, R., and L. Chou, Kinetic study of the dissolution of albite with a continuous flow-through fluidized bed reactor, in The Chemistry of Weathering, NATO Adv. Study Inst. Ser., Ser. $C$, vol. 149, edited by J. I. Drever, pp. 75-96, D. Reidel, Hingham, Mass., 1985.

Wollast, R., and F. T. Mackenzie, The global cycle of silica, in Silicon Geochemistry and Biochemistry, edited by S. R. Aston, pp. 39-76, Academic, San Diego, Calif., 1983.

Zeltner, W. A., E. C. Yost, M. L. Machesky, M. I. TejedorTejedor, and M. A. Anderson, Characterization of anion binding on goethite using titration calorimetry and cylindrical internal reflection-Fourier transform infrared spectroscopy, in Geochemical Processes at Mineral Surfaces, edited by J. A. Davis and K. F. Hayes, ACS Symp. Ser., vol. 323, pp. 142-161, Washington, D. C., 1986.

Zinder, B., G. Furrer, and W. Stumm, The coordination chemistry of weathering, II, Dissolution of Fe(III) oxides, Geochim. Cosmochim. Acta, 50, 1861-1869, 1986.

W. Stumm, EAWAG, CH-8600 Dübendorf, Switzerland.

R. Wollast, Laboratoire d'Océanographie Chimique, Université Libre de Brırelles, Brussels, Belgium. 